\title{
Plasma-Sprayed Hydroxylapatite Coatings as Biocompatible Intermediaries Between Inorganic Implant Surfaces and Living Tissue
}

\author{
Robert B. Heimann ${ }^{1}$
}

Submitted: 8 April 2018/in revised form: 9 June 2018/Published online: 9 July 2018

(c) ASM International 2018

\begin{abstract}
The present contribution discusses critical aspects of the thermal alteration that HAp particles undergo when passing along the extremely hot plasma jet. This heat treatment leads to dehydroxylated phases such as oxyhydroxylapatite/oxyapatite as well as thermal decomposition products such as tri- and tetracalcium phosphates, and quenched phases in the form of amorphous calcium phosphate (ACP) of variable composition. The contribution also includes studying the influence bioinert $\mathrm{TiO}_{2}$ bond coats have on adhesion, crystallinity, and composition of HAp coatings. Moreover, the question is being addressed whether oxyapatite might exist as a (meta)stable phase or whether its occurrence is merely an ephemeral event. In addition, the article deals with the role that HAp coatings are playing during in vitro interaction with simulated body fluid (SBF) resembling the composition of extracellular fluid (ECF). The biological and biomechanical advantages of using HAp coatings for medical implants as well as salient aspects of their biomineralization and osseointegration will be discussed in some detail.
\end{abstract}

Keywords hydroxylapatite coatings - NMR spectroscopy · osseoconductivity $\cdot$ osseoinductivity $\cdot$ oxyapatite $\cdot$ plasma spraying $\cdot$ Raman spectroscopy

Robert B. Heimann

robert.heimann@ocean-gate.de

Görlitz, Germany

\section{Introduction}

About 50 years ago, synthetic hydroxylapatite (HAp) was suggested as a biocompatible material for incorporation in the human body, initially in a passive role to fill congenital bone defects and trauma-induced cavities. Subsequently, hydroxylapatite was introduced in the form of bioactive, i.e., osseoconductive coatings. Their first clinical application was limited to plasma-sprayed coatings for the roots of metallic dental implants, then followed by coatings for the stem of hip endoprostheses, designed to improve implant integration with the surrounding cortical bone. Increasingly, today HAp-based coatings are functionalized by adsorption of non-collagenous bone growth-supporting proteins and antimicrobial drugs to improve their biological efficacy.

Hydroxylapatite (HAp) intended for biomedical purposes has conceptually evolved through three different generations, comprising first-generation crystalline bioinert HAp with solely mechanical and/or space-filling functions, second-generation bioactive and biodegradable coatings to provide osseoconductive functionality to hip and knee endoprostheses, and third-generation HAp designed to stimulate specific cell responses at the molecular level (Ref 1), concentrating on repair and regeneration of damaged or lost tissue based on principles of osseoinduction. Third-generation HAp bioceramics rely on functionalization of the surfaces by bone morphogenetic proteins (BMPs) or other non-collagenous proteins such as osteocalcin, osteopontin and osteonectin, as well as silylated proteoglycans (see "Glossary"). Such proteins provide biochemical signals to bone cells that trigger their proliferation and enhance cell viability and spreading (Ref 2). The adsorption of antimicrobial ions such a silver at the HAp surface is a powerful tool to fight peri- and 
postoperative infections with microbes such as methicillinresistant Staphylococcus aureus (MRSA). Drug-eluting films adsorbed onto hydroxylapatite coatings deposited by low temperature techniques on magnesium alloy-based cardiovascular stents (Ref 3) are novel interventions to prevent neointimal hyperplasia, the major cause of restenosis following percutaneous coronary angioplastic.

Considering this wide and still extending range of application, it is not surprising that hydroxylapatite, $\mathrm{Ca}_{10}\left(\mathrm{PO}_{4}\right)_{6}(\mathrm{OH})_{2}$ (HAp) is among the most frequently studied bioceramic materials in clinical use today. HAp is a hydroxylated calcium orthophosphate with $\mathrm{P}_{3} / \mathrm{m}$ symmetry that is ubiquitously present in Nature as geological phosphate carrier and building material of the shells of marine organisms, and the bones and teeth of vertebrates. However, despite the almost generally accepted notion that the inorganic part of bone is composed of 'hydroxylapatite', this is far from the truth as bone mineral contains at most $15 \%$ of the amount of hydroxyl ions found in mineralogical end-member hydroxylapatite, and some 6 mass \% of carbonate anions and about 3 mass\% of water (Ref 4) as well as $\mathrm{HPO}_{4}{ }^{2-}$ moieties (Ref 5). Nature has designed such calcium- and hydroxyl-deficient, carbonated biological hydroxylapatite (CHAp) with an approximate formula of $\mathrm{Ca}_{10-x}\left(\mathrm{HPO}_{4}\right)_{x}\left(\mathrm{PO}_{4}\right)_{6-x}(\mathrm{OH}, \mathrm{O}, \mathrm{F}, \mathrm{Cl}$, $\left.\mathrm{CO}_{3}\right)_{2-x} \cdot n \mathrm{H}_{2} \mathrm{O} ; 0<x<1,0<n<2.5$ (Ref 6) to provide the mechanical strength and resilience of the gravity-defying bony skeletons of all vertebrates as well as the resistance of teeth to masticatory stresses. In addition to mechanical function, the porous structure of biological hydroxylapatite/collagen I composites allows exchanging essential nutrients via small blood vessels within the Haversian canal of the bone structure that supply blood to osteocytes, i.e., the individual bone cells. Furthermore, bone-like hydroxylapatite supports biologically compatible resorption behavior by osteoclasts and precipitation by osteoblasts under appropriate physical and chemical conditions. And finally, CHAp is a reservoir of phosphorus that can be delivered to the body on demand (Ref 7). In conclusion, hydroxylapatite is of overwhelming importance to sustain life (Ref 8).

To optimize hydroxylapatite with the aim to fulfill a plethora of biological functions when incorporated into the human body, novel developments abound including computational modeling that is being applied to correlate gene expression profiling known as genomics, with combinatorial material design strategies known as materiomics. This approach adds both high throughput capability and additional power to the analysis of biological effects induced by salient biomaterials properties (Ref 9). As a result, many novel material combinations can be rapidly evaluated for their biological efficacy including
HAp coatings of targeted design and with various adsorptive constituents.

Hydroxylapatite-based coatings are the workhorse of modern biomedical implantology. An ever-increasing number of patients receive large-joint reconstructive hip and knee implants to repair the ambulatory knee-hip kinematic. In addition, small-joint and spine implants as well as iliac crest and cheek augmentation are target areas of biomedical implantology using hydroxylapatite coatings and space-filling devices. HAp coatings are being applied for repair and replacement of diseased or missing bone, targeted delivery vehicles of drugs including antimicrobial agents, synthetic bone graft substitutes, and materials for 3D-printed scaffolds. Furthermore, hydroxylapatite-based materials are utilized for edentulous alveolar ridge augmentation, restoration of periodontal defects, and in restorative and preventive dentistry. Recently, a comprehensive review has highlighted the significance of calcium phosphate coatings for de novo bone formation (Ref 10). During the last years, there has been substantially increased interest in nanocomposite materials for biomedical application. Nanocomposites consist of a combination of two or more nanomaterials. By this approach, it is possible to manipulate mechanical properties, such as strength and modulus of the composites, to become closer to those of natural bone (Ref 11). This is feasible by adding secondary substitution phases, frequently of organic nature, that require low temperature deposition techniques. For example, hydroxylapatite/chitosan/carbon nanotubes (Ref 12) and hydroxylapatite/collagen (Ref 13) nanocomposites were deposited by electrophoretic deposition and sol-gel spin coating, respectively.

Since the number of metallic, ceramic and polymeric implants of all kinds supplied worldwide to needy patients are in the range of 10 million annually, the global count of orthopedic surgical interventions increases by 10-12\% annually. At present, the worldwide sales of hip and knee orthopedic surgical joint replacement products are US\$ 16.7 billion, anticipated to reach US $\$ 33$ billion by 2022 (Ref 14), approaching the range of monolithic electronic ceramics.

The present contribution traces the reactions hydroxylapatite powder particles undergo during plasma spraying as well as structural aspects of the reconstruction of thermal decomposition products in contact with simulated body fluid in vitro. In-depth knowledge of these structural changes is essential for successfully designing coating properties with optimum performance in vivo. To explain specific biological and biomedical terms, a glossary has been added to assist the reader unfamiliar with medical nomenclature to understand the complex processes of bone remodeling. 


\section{Deposition of Hydroxylapatite Coatings by Plasma Spraying}

Among a plethora of available deposition techniques, atmospheric plasma spraying (APS) was and still is the method of choice (Ref 15-20) to deposit hydroxylapatite coatings. Much excellent and groundbreaking work in this field has been performed by De Groot et al. (Ref 21), McPherson et al. (Ref 22), Gross and Berndt (Ref 23), Khor et al. (Ref 24), Ding et al. (Ref 25), and many others.

It is generally acknowledged that plasma-assisted deposition techniques excel by a fast, well controlled, economically advantageous, and, in its processing technology, mature way to coat almost any substrate with those materials that exhibit a well-defined congruent melting point (Ref 26). However, the requirement of congruent melting must be relaxed in the present case since hydroxylapatite melts incongruently, i.e., decomposes during melting into tricalcium phosphate $\left(\mathrm{Ca}_{3}\left(\mathrm{PO}_{4}\right)_{2}, \alpha\right.$ - and $\beta$ TCP) and tetracalcium phosphate $\left(\mathrm{Ca}_{4} \mathrm{O}\left(\mathrm{PO}_{4}\right)_{2}, \mathrm{TTCP}\right)$, or even cytotoxic calcium oxide, $\mathrm{CaO}$ following evaporative loss of $\mathrm{P}_{2} \mathrm{O}_{5}$. Moreover, a large proportion of the molten powder material solidifies on contact with the relatively cool implant surface to form easily soluble amorphous calcium phosphate (ACP) of various compositions (Ref $27,28)$. On the one hand, this amorphous calcium phosphate layer adjacent to the substrate interface reduces coating adhesion to the implant surface in vivo. As it constitutes a path of least energy parallel to the interface, separation and coating delamination may easily occur, jeopardizing the clinical success of the implant. On the other hand, ACP is being involved in formation of secondary, bone-like apatite in vivo, owing to its pronounced solubility in body fluid and thus, its ability to provide a fertile environment for nucleation of HAp from the extracellular fluid (ECF) supersaturated with respect to HAp.

Despite the advantages mentioned above, there are serious disadvantages of using atmospheric plasma spraying (APS) to deposit biomedical hydroxylapatite coatings. First, owing to the compositional changes induced by rapid heating of HAp powder to extremely high temperatures, biomedical coatings deposited by thermal spray techniques exhibit properties that differ substantially in chemical and phase composition, crystallinity, crystallite size, and defect density compared to natural bone-like apatite. Second, conventional APS is unable to provide coatings with thickness less than about $20 \mu \mathrm{m}$, a property that frequently does not meet medical requirements. To achieve thinner coating layers, recently suspension (SPS) and solution precursor plasma spraying (SPPS) techniques were developed (Ref 29-31). Third, line-of-sight limitations render coating of geometrically complex substrate shapes difficult and inefficient, and undesirable local heating of the implant substrate may affect its metallic microstructure. This pertains, for example, to the forced $\alpha / \beta$ transition of alloyed titanium at high temperature, i.e., in direct contact with the hot plasma jet. Fourth, plasma spraying results in rather dense coating layers that may be unable to satisfy biomedical requirements calling for pore sizes in excess of the $75 \mu \mathrm{m}$ that are necessary to guarantee unimpeded ingrowth of bone cells (Ref 32-34). Indeed, deposition of dense, stoichiometric, and highly crystalline hydroxylapatite coating layers is, from a biomedical point of view, frequently ineffective since those coatings tend to be bioinert as they have lost their osseoconductive property that is based on sufficient solubility. To remedy this drawback, SPS can be applied, a novel coating technique able to provide the degree of coating porosity required to sustain adequate bone cell ingrowth and solubility (Ref 29, 30).

To introduce osseoconductive functionality, hydroxylapatite coatings need to have some degree of non-stoichiometry, expressed by $\mathrm{Ca}$ deficiency caused by substitution of $\mathrm{Ca}$ cations by metabolically important elements such as $\mathrm{Mg}, \mathrm{Sr}, \mathrm{Na}, \mathrm{K}$ and others, as well as substitution of carbonate ions for orthophosphate (type-B defect) or hydroxyl (type-A defect) anions (Ref 35, 36). Such non-stoichiometric, substituted, disordered, and sparingly soluble nano-crystalline carbonated hydroxylapatite (n-CHAp) closely resembles so-called 'bone-like' biological apatite with the approximate formula $\mathrm{Ca}_{10-x}(-$ $\left.\mathrm{HPO}_{4}\right)_{x}\left(\mathrm{PO}_{4}\right)_{6-x}\left(\mathrm{OH}, \mathrm{O}, \mathrm{Cl}, \mathrm{F}, \mathrm{CO}_{3}, \square\right)_{2-x} \cdot n \mathrm{H}_{2} \mathrm{O}$; $0<x<1 ; 0<n<2.5$ (Ref 37). Recently, Pasteris (Ref 4) has pointed out similarities and differences between biological apatite and the calcium phosphate phases typically synthesized as biomaterials. From this, it is apparent that there still is a discrepancy between existing spray precursor materials and desired coating composition in terms of chemical and mechanical properties, and their biological efficacy.

Despite the shortcomings mentioned above, plasma spraying is still the method of choice to deposit HAp coatings on the stem of commercially supplied hip endoprostheses as well as the roots of dental implants. Currently, plasma spraying of hydroxylapatite powder particles with diameters of tens to hundreds of micrometers is the most popular and the only Food and Drug Administration (FDA)-approved method to coat implant surfaces for clinical use (Ref 38, 39). However, even though plasma spray deposition of HAp coatings is regarded a mature and well research-supported technique, there is a need to address, research, and remedy several disadvantages and obvious deficiencies. Consequently, today many attempts are being made toward optimization of essential properties 
of osseoconductive bioceramic coatings, deposited by APS. These properties include coating cohesion and adhesion, phase composition, homogeneous phase distribution, crystallinity, porosity and surface roughness, nano-structured surface morphology, residual coating stress, and coating thickness (Ref 15, 40, 41). Comprehensive accounts on optimizing deposition strategies of plasmasprayed hydroxylapatite coatings for medical implants have been recently reviewed by the present author (Ref 1820).

\section{Biological and Biomechanical Benefits of Hydroxylapatite Coatings}

Plasma-sprayed hydroxylapatite coatings, deposited on the stem of hip endoprosthetic implants, have achieved longterm survival in the human body, provided that requirements are met that include suitable selection of implant type, appropriate choice of bearing surfaces based on the patient's age and life expectancy, state-of-the-art surgical technique, and adequate bone quality (Ref 42). Chen et al. (Ref 43) have provided a meta-analysis of twenty-one follow-up studies, confirming that hydroxylapatite coatings improved significantly the postoperative Harris hip score (Ref 44) when compared to the long-term performance of stems coated with porous titanium. Many clinical studies and long-term statistical evaluation of the outcome of periodontal and arthroplastic implantations are available that show the positive effects of hydroxylapatite coatings on osseointegration (Ref 45-52). However, there are also dissenting views (Ref 53, 54).

Based on the clinical outcome of hundreds of total hip replacement (THR) operations, HAp-coated implants are still considered the current 'gold standard' in hip arthroplasty and dental restoration (Table 1). Such success is achieved, in spite of the coating shortcomings elucidated above, by careful design of coatings aimed at minimizing the negative impacts on coating functionality and longevity. Important tools to optimize coatings are based on principles of Statistical Design of Experiment strategies. In addition, increased power of prediction of coating performance can be gained from the application of artificial neuronal networks, generic algorithms, and fuzzy logic control validated either by key experiments or first-principle calculations (Ref 55).

Among the major advantages of hydroxylapatite coatings listed in Table 1 is the absence of a fibrillar layer of connective tissue adjacent to the implant surface. This ensures continuous and strong bone apposition with adhesion strengths beyond $35 \mathrm{MPa}(\operatorname{Ref} 33)$ as clearly shown in Fig. 1. The undesirable acellular connective tissue capsule frequently forms around a metallic or ceramic implant body in the absence of a mediating coating, thus impeding a lasting osseointegration (Fig. 1a). In contrast to this, Fig. 1(b) shows the advantageous biomedical function of a hydroxylapatite coating that prevents formation of a connective tissue layer, leading to strong and continuous connection between implant and new bone.

\section{Basic Aspects of Biomineralization and Osseointegration of Hydroxylapatite Coatings}

The process of biomineralization is characterized by a sequence of complex interaction of inorganic solids such as hydroxylapatite, calcite, and aragonite with organic structure-mediating template matrices and can be viewed as a succession of four consecutive steps (Ref 60).

Initially, the organism provides an appropriate reaction volume during a supramolecular pre-organization step. Frequently, mineralization takes place in a macromolecular network with properties akin to a gel-like structure. Within this network, specific areas exist the molecular properties of which trigger the deposition of biominerals via molecular surface recognition. The third step is characterized by nucleation and crystal growth during which size and orientation of the crystals are being controlled by the structure and molecular organization of the organic matrix template (vectorial regulation). The simplest form of vectorial regulation is provided by the spatial limitation of the reaction volume within which the process of biomineralization occurs. More precisely, vectorial regulation is the result of structuring of the extracellular matrix (ECM). Finally, mesoscopic and macroscopic structural developments of the products of biomineralization lead to more complex, hierarchically organized solids such as shells, bones, and teeth (cellular construction).

The remarkable mechanical properties of the products of biomineralization such as high compressive and flexural strength, elasticity, and fracture toughness are caused by the controlled assembly of individual mineral segments to form an organized superstructure (Ref 61), whereby the specific action of the organic template matrix is the key to understanding biomineralization. Bones and teeth are heterogeneous, hierarchical, composite structures consisting of biological hydroxylapatite and matrix proteins, predominantly collagen I. Collagen macromolecules are composed of three collagen polypeptide chains coiled into a repeating triple-helical fibril and associated with noncollagenous proteins such as osteocalcin, osteopontin and bone sialoprotein. Human bones consist of a hierarchically organized assembly of about $70 \%$ of nano-crystalline biological apatite, and $30 \%$ of microfibrils of collagen I. Nanocrystals of biological apatite of about $30 \times 50 \times 2 \mathrm{~nm}^{3}$ size are arranged with their 
Table 1 Advantages of hydroxylapatite coatings (Ref 15)

\begin{tabular}{|c|c|}
\hline \multirow[t]{3}{*}{ Mechanical properties } & $\begin{array}{l}\text { Strong bonding between implant and bone with tensile strengths up to } 100 \mathrm{MPa} \text {, depending on } \\
\text { coating thickness and microstructure }\end{array}$ \\
\hline & $\begin{array}{l}\text { Thickness of coating can be selected between } 50 \text { and } 250 \mu \mathrm{m} \text {, depending on application. Thinner } \\
\text { coatings below } 20 \mu \mathrm{m} \text { can be deposited by suspension (SPS) or solution precursor plasma } \\
\text { spraying (SPPS) }\end{array}$ \\
\hline & Rarely problems with coating delamination or spalling in vivo \\
\hline \multirow[t]{3}{*}{ Chemical properties } & Reduction of release of cytotoxic metal ions from the coated implant surface \\
\hline & Limited protection of implant metal against corrosion by biofluid in vivo \\
\hline & Suitable resorption resistance of coatings in contact with biofluid \\
\hline \multirow[t]{2}{*}{ Design variability } & Variable metallic implant materials possible (Ti alloys, CoCrMo alloy, surgical austenitic steels) \\
\hline & $\begin{array}{l}\text { Variable surface structures possible (mesh, artificial spongiosa, beaded } \mathrm{Ti} \text {, roughened/micro- } \\
\text { patterned surfaces by etching or laser treatment) }\end{array}$ \\
\hline \multirow{9}{*}{ Biological properties } & High biocompatibility \\
\hline & Superior bioactivity \\
\hline & Faster and improved osseointegration \\
\hline & Absence of fibrillar space-filling connective tissue surrounding the implant (see Fig. 1b) \\
\hline & Reduced incidence of femoral osteolysis \\
\hline & Osseointegration possible even during patient-induced micro-motion during healing phase \\
\hline & $\begin{array}{l}\text { Coating supports ingrowth of bone cells, blood capillaries, and perivascular tissue into gap } \\
\text { between implant and bone (osseoconductivity) }\end{array}$ \\
\hline & In the presence of adsorbed bone growth-supporting proteins, high osseoinductive potential \\
\hline & Improved Harris hip score (HHS) \\
\hline \multirow[t]{2}{*}{ Satisfaction of patients } & Reduced incidence of thigh pain \\
\hline & Promotion of earlier implant loading after healing phase \\
\hline Quality control & $\begin{array}{l}\text { Standards available according to ASTM F 1185-03 (Ref 56), ISO } 13485 \text { (Ref 57) and others (Ref } \\
58 \text { ) designations }\end{array}$ \\
\hline
\end{tabular}

crystallographical c-axes parallel to the long axes of five collagen I molecules consisting of triple-helical strands of collagen fibers each to form a higher level microfibril. These inorganic-organic composite microfibrils are bundled together to form even larger fibrils that are grouped to still larger mineralized fibers, eventually forming an osteon, the smallest functional basic unit of a cortical bone.

The cellular regulation of the mineralization process relies on specialized cell types such as osteoblasts, osteocytes, chondrocytes, and odontoblasts that control the flux of ions into the extracellular matrix (ECM), and register signals that regulate the start and end of the mineralization process. The ECM itself makes available an oriented surface for deposition of bone mineral and controls, in concert with non-collagenous proteins, the shape and size of the nano-sized crystals of biological hydroxylapatite. Hence, the ECM provides the required reaction volume, the ionic functional groups of non-collagenous proteins influence nucleation of biominerals, and the spatial organization of the products of mineralization within the network supports their meso- or macroscopic structure expression toward higher hierarchical order.

The timeline of basic steps occurring at the interface between implant and bone during osseointegration in the presence of an osseoconductive hydroxylapatite coatings can be summarized as follows: (1) formation of a thrombus after approximately 2 days, (2) tissue reorganization by formation of a callus after approximately 6 days, (3) phenotypical expression of undifferentiated cells toward osteocytes, and (iv) bone remodeling within 4-6 months. This requires that interface reactions of de novo osteoblasts be influenced and partially controlled by intrinsic hydroxylapatite coating properties such as phase composition, degree of crystallinity, surface microstructure including roughness and porosity, and the presence of metabolically important trace elements and bone growth-supporting proteins. The ability of hydroxylapatite-based bioceramic materials to mediate some of the processes mentioned above are generally attributed to five intrinsic coating properties: (i) chemical composition resembling that of biological apatite, (ii) micro- or nano-structured surface topography, (iii) appropriate macro- and microporosity to facilitate bone cell ingrowth and revascularization, (iv) enhanced adhesion to the metallic implant substrate, and (v) controllable dissolution kinetics to provide an environment beneficial for advanced nucleation. Thus, calcium phosphate osseogenicity relies on $\mathrm{Ca}^{2+}$ and $\left[\mathrm{PO}_{4}\right]^{3-}$ ions released from dissolving hydroxylapatite coatings during 


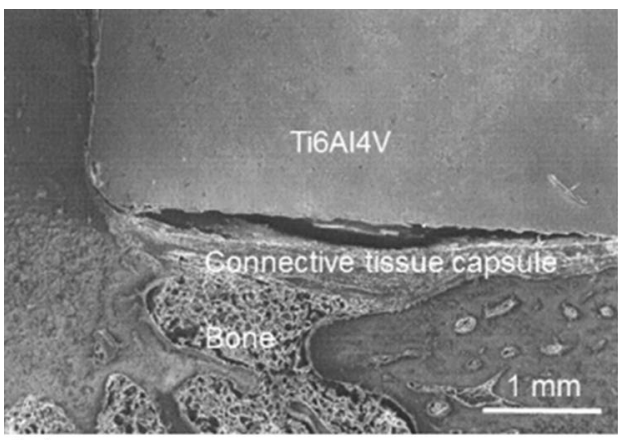

(a)

Fig. 1 The in vivo function of hydroxylapatite-based implant coatings after an observation time of 6 months. (a) An uncoated Ti6Al4V cube $\left(5 \times 5 \times 5 \mathrm{~mm}^{3}\right)$, surgically implanted into the lateral condyle of a canine femur, shows encapsulation by a thick non-adhering layer of connective tissue (center) separating the implant (top) from the cortical bone bed (bottom). The sample preparation-imposed gap

interaction with body fluid that profoundly affect the migration, proliferation and differentiation of osteoblasts during de novo bone formation. In addition, hydroxylapatite coatings appear to promote normal cell differentiation in surrounding tissues by providing a fertile environment for enhanced cell adhesion (Ref 62) and biocompatibility, including reduction of bacterial adhesion in dental implantology (Ref 63).

In addition to the precipitation kinetics, the morphology of HAp micro- or nanocrystals, in particular their aspect ratio, will be affected by epi- and/or topotactical adsorption of organic constituents such as poly (amino acids) at energetically favored lattice planes of HAp crystallites. Adsorption of poly (L-lysine) on the $\{001\}$ planes of HAp causes formation of polycrystalline nanocrystals, whereas adsorption of poly (L-glutamic acid) leads to large and flat micron-sized single crystals (Ref 64). Similarly, the amino acids glycine and glutamic acid were experimentally found to lead to the formation of rod- and plate-like hydroxylapatite crystallites, respectively (Ref 65). Whereas the amino acids adsorbed on $\{001\}$ and $\{100\}$ faces occupied vacant $\mathrm{Ca}$ sites with their positive amino groups, their negative carboxylate groups occupied vacant $\mathrm{P}$ or $\mathrm{OH}$ sites, forming an ordered adsorption layer. Glutamic acid was found to adsorb strongly to the $\{001\}$ faces of HAp, resulting in formation of plate-like crystallites. Conversely, the degree of adsorption of proteins such as bovine serum albumin (BSA) and lysozyme (LSZ) was found to be strongly dependent on hydroxylapatite particle morphology, i.e., plate- or rod-like particles provided different adsorption sites of Langmuirian type and thus, specific surface areas (Ref 66). In contrast to these findings involving the action of biomolecules, aqueously precipitated carbonated, hydrated, calcium- and hydroxyl-

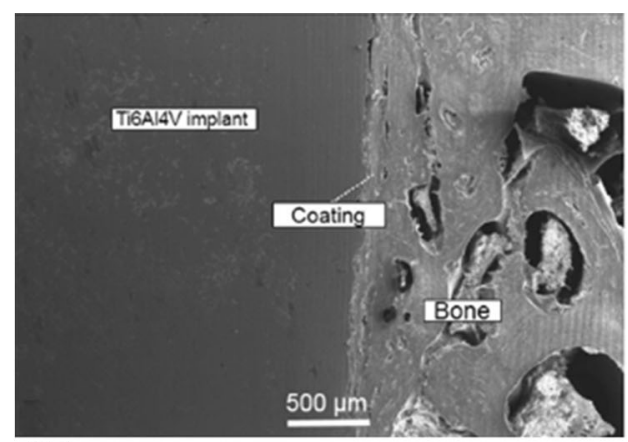

(b)

demonstrates the poor adhesion of the connective tissue layer to the implant surface. (b) A hydroxylapatite-coated Ti6Al4V cube $\left(5 \times 5 \times 5 \mathrm{~mm}^{3}\right)$, implanted into the same position as in (a), reveals strong and continuous connection of implant (left) and cortical bone (right) (Ref 59)

deficient apatite without organic adsorbents showed also the size and shape of typical biological apatite. Apparently, carbonate incorporation into the HAp lattice suffices to control the size and shape of crystals toward those of bonelike apatite even without the mediating action of organics (Ref 4).

The bone growth-stimulating function of hydroxylapatite coatings can further be expressed by the terms osseoconductivity and osseoinductivity. On the one hand, osseoconductivity is the ability of a biomaterial to support the ingrowth of bone cells, blood capillaries, and perivascular tissue into the operation-induced gap between implant body and existing cortical bone bed. Interconnected coating pores of 100-300 $\mu \mathrm{m}$ size foster the process of osseogenesis and osseointegration, thus underscoring the need to design, enhance and control pore sizes in plasmasprayed HAp coatings. On the other hand, 'osseoinductivity' refers to the ability to transform undifferentiated mesenchymal precursor stem cells into osseoprogenitor cells that precede endochondral ossification. This process relies crucially on the action of non-collagenous proteins. Hydroxylapatite will adsorb extracellular specific adhesion molecules in a favorable conformation and thus, promote the formation of focal adhesion centers. Bone growth factors and cytokines will also be adsorbed at specific sites of hydroxylapatite surfaces, thus further promoting osseointegration.

Figure 2 shows an extremely simplified schematic representation of osseoinduction, triggered by adsorption and incorporation of cell membrane proteins into the bone-like hydroxylapatite layer precipitated onto the dissolving calcium phosphate coating. Increased concentrations of $\mathrm{Ca}^{2+}$, $\mathrm{PO}_{4}{ }^{3-}$ and $\mathrm{HPO}_{4}{ }^{2-}$ ions stimulate chemotactical release of chemokines from the cortical bone bed (Ref 67). With 


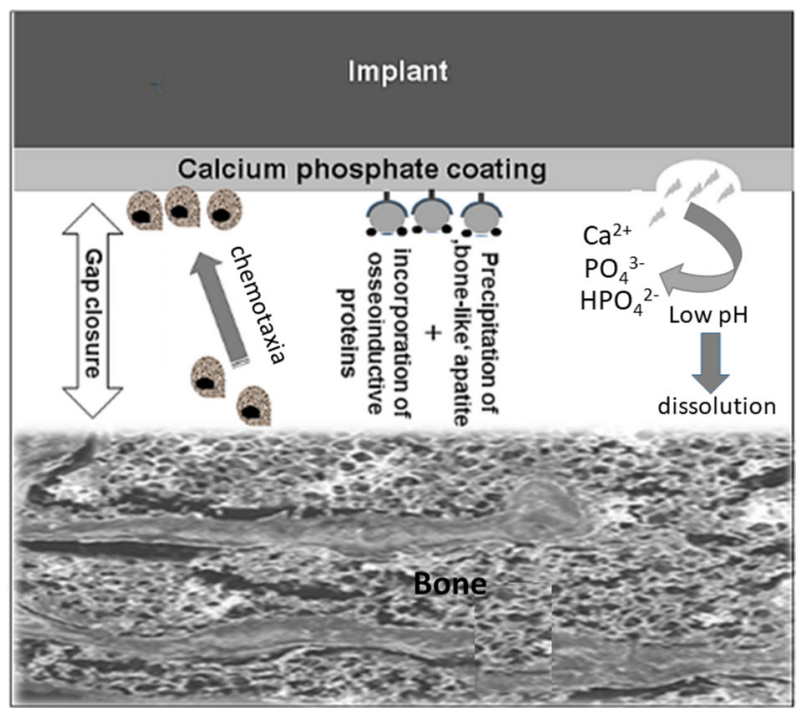

Fig. 2 Schematics of the interaction between implant and living bone cells, mediated by a thin calcium phosphate coating (adapted from Ref 67). The local decrease of $\mathrm{pH}$ triggers partial dissolution of the coating (right), thus effecting the concurrent release of chemotaxia (agents promoting cell migration) from bone (left). Addition of $\mathrm{Ca}^{2+}$ and $\mathrm{PO}_{4}{ }^{3-}$ ions leads to increased supersaturation of the ECF with respect to hydroxylapatite. This process results in nucleation and precipitation of 'bone-like' biological apatite, and subsequent adsorption of bone growth-supporting proteins (center). The gap width between bone and implant shown here is highly exaggerated and hence, not to scale

time, bone growth-supporting proteins adsorbed at the coating surface will give rise to osseointegration by proliferation of stem cells and their differentiation toward bone cells, revascularization, and eventual gap closure and healing. Gap closure happens from two sides as new bone grows into the gap from cortical bone as well as from the implant surface.

On a cellular level, apatite precipitation is thought to start with nucleation of calcium phosphate proto-nuclei from the extracellular fluid (ECF), supersaturated with respect to hydroxylapatite. Ab initio calculations by Onuma et al. (Ref 68) suggested that the first product of precipitation is composed of so-called Posner's clusters, $\left\{\mathrm{Ca}_{3}\left(\mathrm{PO}_{4}\right)_{2}\right\}_{3}$ with an energetically most favored and hence, most stable configuration. Carboxylate ligands such as citrate and oxalate anions were found to delay the onset of HAp nucleation, whereas non-collagenous proteins such as osteocalcin, osteonectin and bone sialoprotein, and proteoglycans such as hyaluronic acid and chondroitin sulfate favor enhanced nucleation (Ref 69). Osteocalcin in particular shows high affinity for HAp and appears to play a significant role in cell signaling for bone formation (Ref 70).

The cellular origin of bone mineralization is rooted in cellderived matrix vesicles by major influx of calcium and phosphate ions into the cells (Ref 71). Production of phosphatidylserine-calcium phosphate complexes (Ref 72) within the plasma membrane of the vesicles is mediated by several proteins including annexins, integrins, and alkaline phosphatase. These proteins cleave phosphate groups off phosphatidylserine and in this way act as preferential sites of calcium phosphate precipitation. Hence, $\mathrm{Ca}^{2+}$ cations bound to phospholipids, and $\mathrm{PO}_{4}{ }^{3-}$ and $\mathrm{HPO}_{4}{ }^{2-}$ anions released from phosphatidylserine and dissolving HAp, respectively, combine to form initially amorphous calcium phosphate (ACP) nuclei that subsequently grow to become nano-crystalline hydroxylapatite at specific sites of the vesicle membrane (Ref 73). Then, matrix vesicles bud from the plasma membrane during interaction with the extracellular matrix (ECM), providing calcium and phosphate ions, lipids, and proteins that act to nucleate apatite. This process is presumably tightly controlled by the speciation of the phosphate carrier: pyro $\left[\mathrm{P}_{2} \mathrm{O}_{7}\right]^{4-}$ - and polyphosphate $\left[\mathrm{P}_{n} \mathrm{O}_{3 n+1}\right]^{(n+2)-}$ ions were found to inhibit mineralization, whereas hydrogen phosphate $\left[\mathrm{HPO}_{4}\right]^{2-}$ ions appear to stimulate nucleation even outside the matrix vesicles in the extracellular matrix and also directly on the triple-helical collagen I strands that are part of the composite structure of biological apatite.

\section{Thermal Decomposition Reactions of Hydroxylapatite During Plasma Spraying}

\section{Incongruent Melting of Hydroxylapatite}

Hydroxylapatite powder particles subjected to the high temperature of a plasma jet undergo, even during their very short residence time of hundreds of microseconds to few milliseconds, first dehydroxylation and subsequently, thermal decomposition by incongruent melting. As shown in Table 2, this thermal decomposition sequence occurs in four consecutive steps.

Several models were developed (Ref 74-76) of the inflight evolution of individual calcium phosphate phases. Figure 3 displays two models of thermally induced phase transformation within a spherical hydroxylapatite particle at various water partial pressures, considering a parabolic temperature gradient according to Fourier's Law (Ref 77). During the short residence time of the particle in the plasma jet, its core remains still at a temperature well below $1550{ }^{\circ} \mathrm{C}$, this being the result of the low thermal diffusivity of hydroxylapatite of about $4.5 \times 10^{-3} \mathrm{~cm}^{2} / \mathrm{s}$ at $1000{ }^{\circ} \mathrm{C}$ (Ref 78). Consequently, hydroxylapatite (HAp) and oxyhydroxylapatite/oxyapatite (OHAp/OA) are the only solid phases present (Table 2, steps 1 and 2).

At a high water partial pressure (Fig. 3, left), the shell surrounding the solid core heated to a temperature above the incongruent melting point of hydroxylapatite $\left(1570{ }^{\circ} \mathrm{C}\right)$ consists of a molten mixture of tri- and tetracalcium phosphates (Table 2, reaction 3). The following outermost 
Table 2 Thermal decomposition sequence of hydroxylapatite

\begin{tabular}{|c|c|}
\hline Step 1 & $\underset{\text { (hydroxyapatite) }}{\mathrm{Ca}_{10}\left(\mathrm{PO}_{4}\right)_{6}(\mathrm{OH})_{2}} \rightarrow \underset{\text { (oxyhydroxyapatite) }}{\mathrm{Ca}_{10}\left(\mathrm{PO}_{4}\right)_{6}(\mathrm{OH})_{2-2 x} \mathrm{O}_{x} \square_{x}}+x \mathrm{H}_{2} \mathrm{O}$ \\
\hline Step 2 & $\underset{\text { (oxyhydroxyapatite) }}{\mathrm{Ca}_{10}\left(\mathrm{PO}_{4}\right)_{6}(\mathrm{OH})_{2-2 x} \mathrm{O}_{x} \square_{x}} \rightarrow \underset{\text { (oxyapatite) }}{\mathrm{Ca}_{10}\left(\mathrm{PO}_{4}\right)_{6} \mathrm{O}_{x} \square_{x}+(1-x) \mathrm{H}_{2} \mathrm{O}}$ \\
\hline Step 3 & 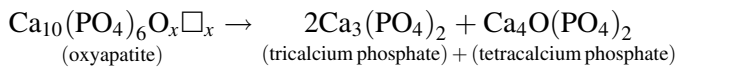 \\
\hline Step $4 \mathrm{a}$ & $\mathrm{Ca}_{3}\left(\mathrm{PO}_{4}\right)_{2} \rightarrow 3 \mathrm{CaO}+\mathrm{P}_{2} \mathrm{O}_{5}$ \\
\hline Step 4b & $\mathrm{Ca}_{4} O\left(\mathrm{PO}_{4}\right)_{2} \rightarrow 4 \mathrm{CaO}+\mathrm{P}_{2} \mathrm{O}_{5}$ \\
\hline
\end{tabular}

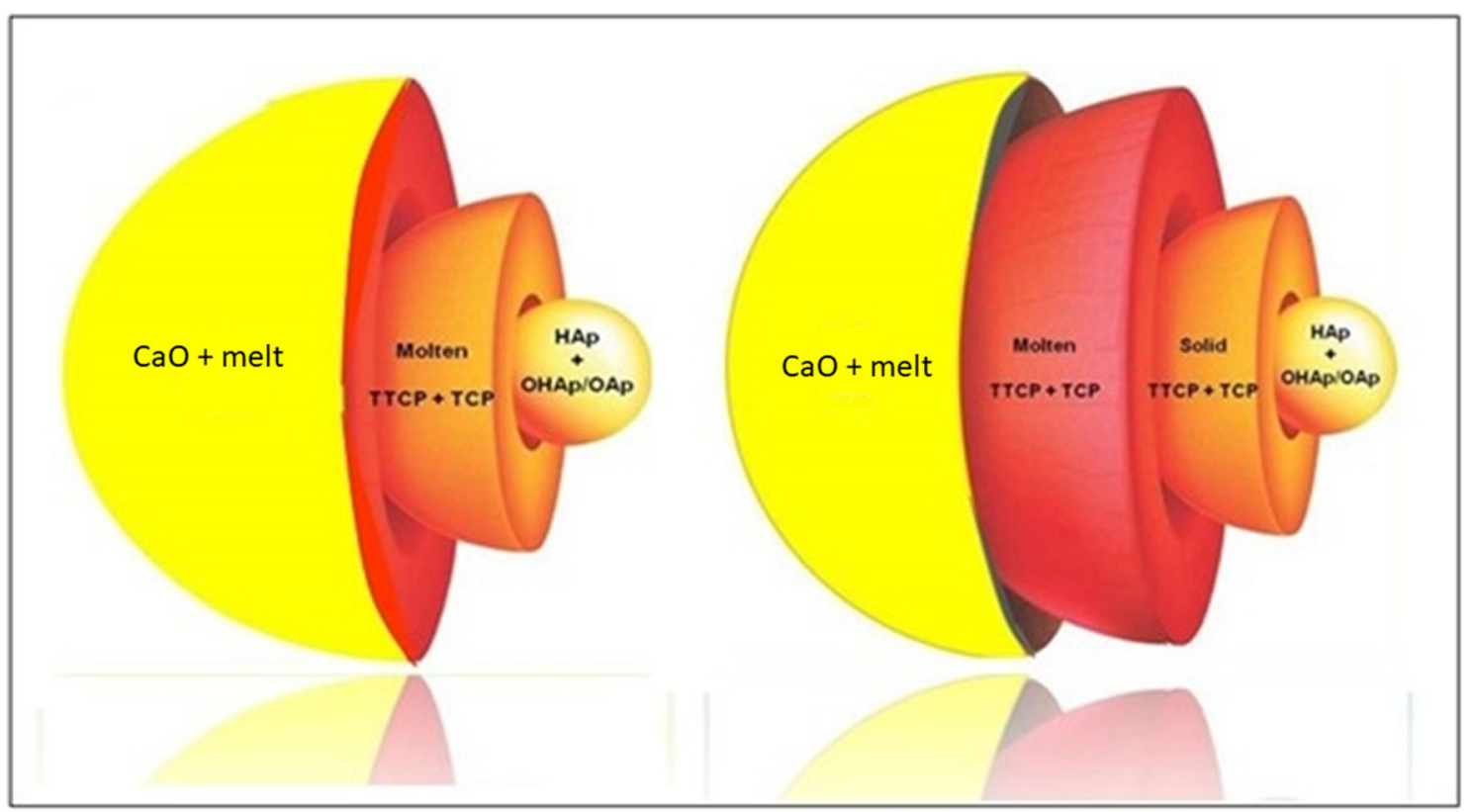

Fig. 3 Schematic models of the thermal decomposition of a spherical hydroxylapatite particle during plasma spraying. Left: at high water partial pressure of $65.5 \mathrm{kPa}$ (Ref 79). Right: at low water partial pressure of $1.3 \mathrm{kPa}(\operatorname{Ref} 81)$

spherical shell of the particle comprises solid $\mathrm{CaO}$ and melt since evaporation of $\mathrm{P}_{2} \mathrm{O}_{5}$ or, more likely, loss of $\mathrm{P}$ generated by reduction of $\mathrm{P}_{2} \mathrm{O}_{5}$ in the $\mathrm{H}_{2}$-rich plasma plume (Ref 80) shifts the composition along the liquidus curve (Fig. 4, left) toward CaO-richer phases (Table 2, reaction 4). The temperature increases to well beyond $1800{ }^{\circ} \mathrm{C}$, and the only unmelted composition is $\mathrm{CaO}$. At low water partial pressure (Fig. 3, right), the situation is different. As experimentally shown by Dyshlovenko et al. (Ref 81), solid-state dehydration transformation of HAp into TCP and TTCP occurs between 1360 and $1570{ }^{\circ} \mathrm{C}$ (Fig. 4b). Hence, the second shell heated to a temperature of $1360<T<1570{ }^{\circ} \mathrm{C}$, just below the incongruent melting point of HAp, undergoes solid-state decomposition to a mixture of $\alpha^{\prime}$-TCP and TTCP.

Figure 4 shows the binary phase diagram of the system $\mathrm{CaO}-\mathrm{P}_{2} \mathrm{O}_{5}$ with the region of particular interest around the composition of apatite highlighted in shading (Ref 82).
The molten phase comprising the outermost shell of the heated HAp particle (Fig. 3) is quenched on impact with the comparatively cool substrate surface and thus will solidify rapidly to produce $\mathrm{ACP}$ with various $\mathrm{Ca} / \mathrm{P}$ ratios (Ref 83-85). The force of impact of droplets accelerated to supersonic velocity triggers a series of events that profoundly affect the composition and the morphology of the resulting coating. On impact, the neatly ordered succession of spherical shells shown in Fig. 3 will be destroyed and thus, will form a mixture of intermingled phases, i.e., ACP in close vicinity to hydroxylapatite and oxyhydroxylapatite (Fig. 5, right). Patches of ACP are being scattered throughout the crystalline calcium phosphate phases as shown in Fig. 5, right, in an SEM micrograph in cathodoluminescence (CL) mode (Ref 86). This patchy distribution of ACP is the result of the splashing of molten or semi-molten droplets during impact at the substrate surface whereby the ACP will be folded into the crystalline 


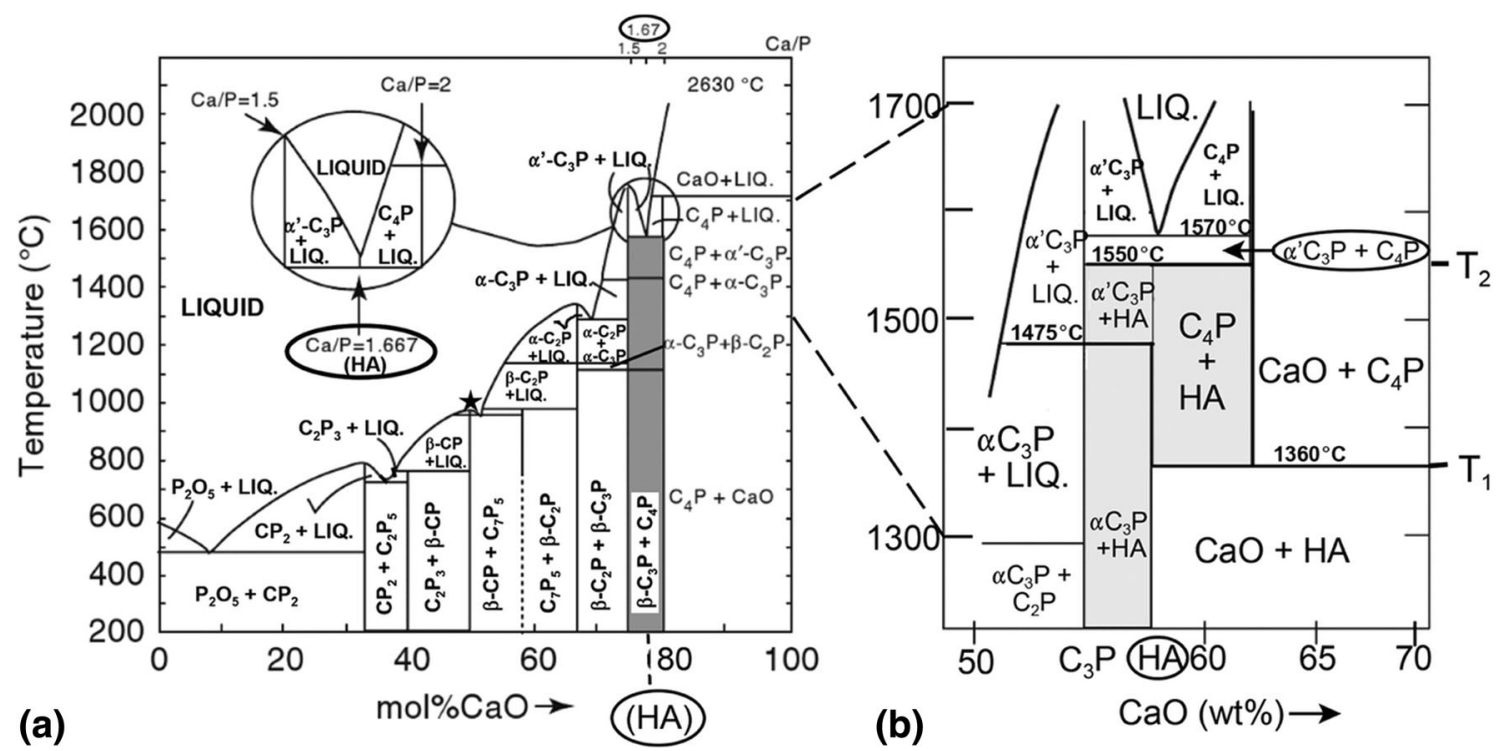

Fig. 4 (a) Binary phase diagram $\mathrm{CaO}-\mathrm{P}_{2} \mathrm{O}_{5}$ in the absence of water (Ref 82). The inset shows the region of interest (incongruent melting of $\mathrm{HAp}$ ). (b) Binary phase diagram $\mathrm{CaO}-\mathrm{P}_{2} \mathrm{O}_{5}$ at water partial pressure of $65.5 \mathrm{kPa}$, showing the incongruent melting of $\mathrm{HAp}$ beyond $1570{ }^{\circ} \mathrm{C}$ under formation of $\alpha-\mathrm{C}_{3} \mathrm{P}(\alpha-\mathrm{TCP})$ and $\mathrm{C}_{4} \mathrm{P}$ (TTCP). The compositions are given in so-called cement notation: $\mathrm{C}=\mathrm{CaO}$, $\mathrm{P}=\mathrm{P}_{2} \mathrm{O}_{5}$
Fig. 5 SEM images in backscattered electron (BSE) mode (left) and cathodoluminescence (CL) mode (right) of a plasmasprayed HAp coating immersed for 7 days in simulated body fluid (HBSS). The dark areas are predominantly composed of ACP (Ref 86)
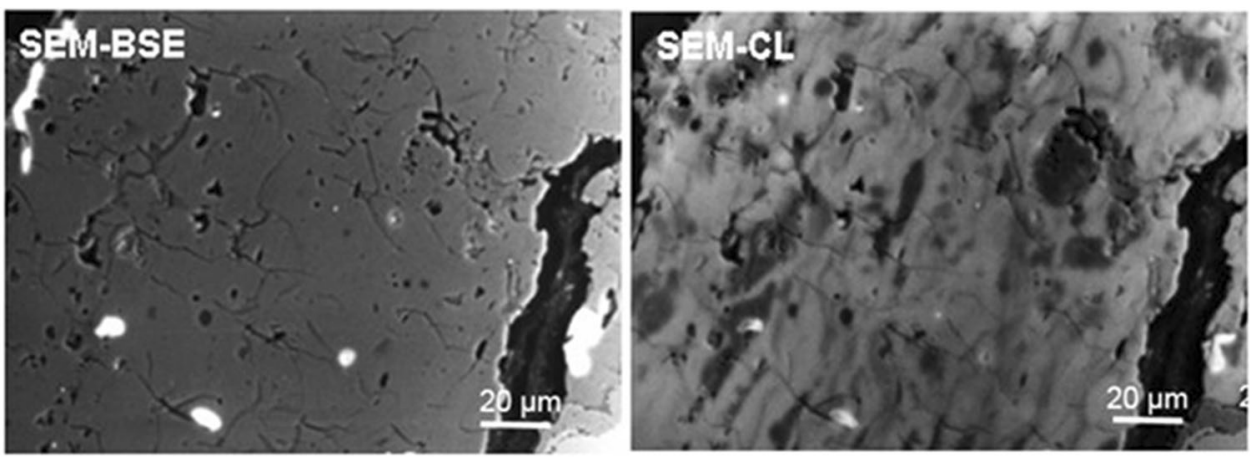

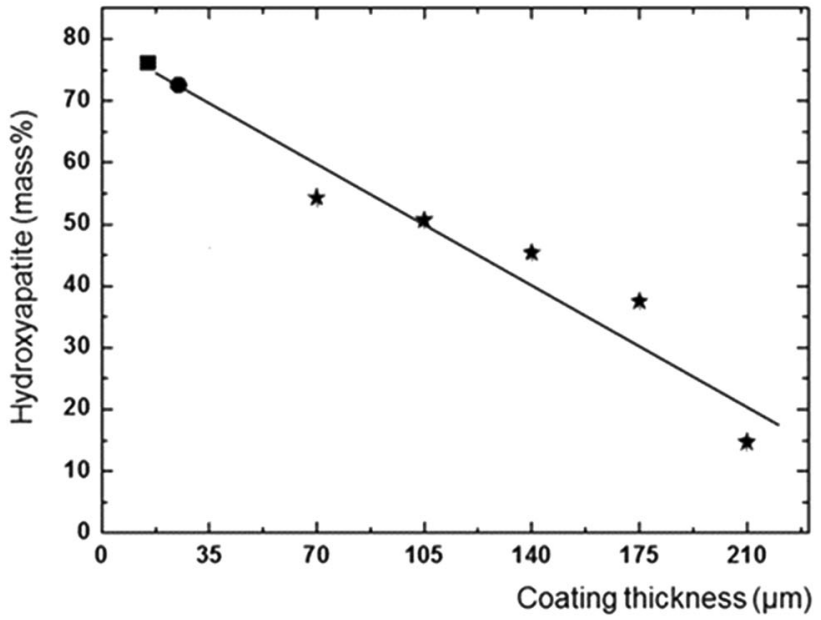

Fig. 6 Left: Linear decrease of HAp content with coating thickness. Right: Exponential decrease of crystallinity of a plasma-sprayed HAp coating with coating thickness. The coefficients of the exponential decay equation were determined to be $a=128.3$, and $b=14.3$. The

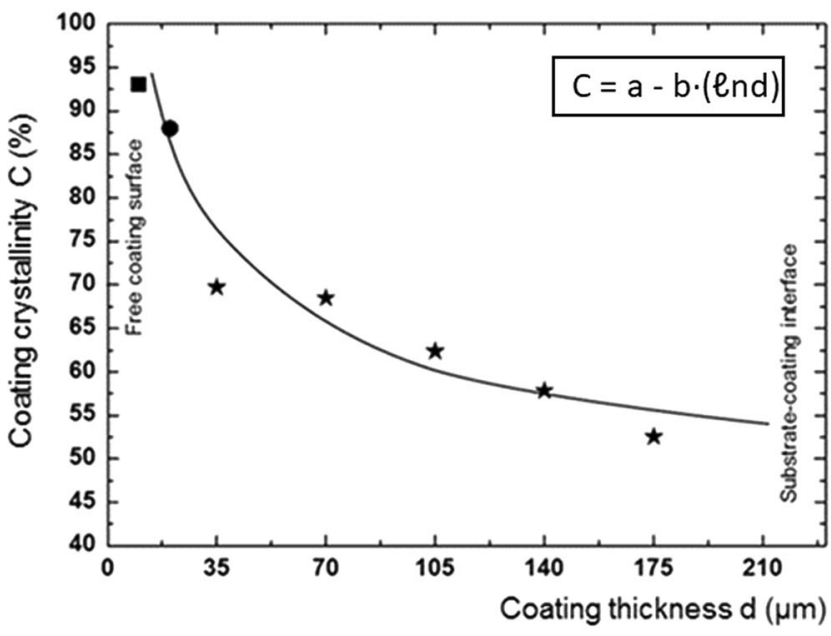

data were obtained by conventional $\mathrm{x}$-ray diffraction $(8 \mathrm{keV}$, square) and synchrotron radiation $\mathrm{x}$-ray diffraction $(11 \mathrm{keV}$, dot; $100 \mathrm{keV}$, stars) (Ref 88) (C) With permission by Elsevier 
constituents. Scanning cathodoluminescence microscopic microanalysis of coatings conducted by Gross and Phillips (Ref 87) confirmed that the darker regions in polished cross sections represent the amorphous phase as shown in Fig. 5, right. The more intense cathodoluminescence emission from the amorphous phase during electron beam irradiation compared with the lighter appearing crystalline phase can thus be used to distinguish between structurally ordered (crystalline) and disordered (amorphous) areas within the sample. By selecting the peak of the intrinsic electron emission at $450 \mathrm{~nm}$, it is possible to scan the surface with the electron beam, producing a map of ACP in polished sections. Hence, cathodoluminescence microscopy based on the different light emission from the amorphous phase and hydroxylapatite is a useful tool to identify and map the ACP constituent in plasma-sprayed coatings (Ref 15).

In addition to the compositional inhomogeneity caused by lateral splat spreading, the phase composition of the coating also varies with coating depth. Depth-resolved diffraction studies with both conventional x-ray and synchrotron radiation energies revealed that the content of hydroxylapatite decreases linearly with coating depth from approximately 75 mass $\%$ at the free coating surface to $15 \mathrm{mass} \%$ at the coating-substrate interface (Fig. 6, left). Moreover, at the free coating surface, the remainder of crystalline phases were determined to be 15 mass\% TTCP, 4 mass\% B-TCP, and 1.5 mass\% $\mathrm{CaO}$. These values

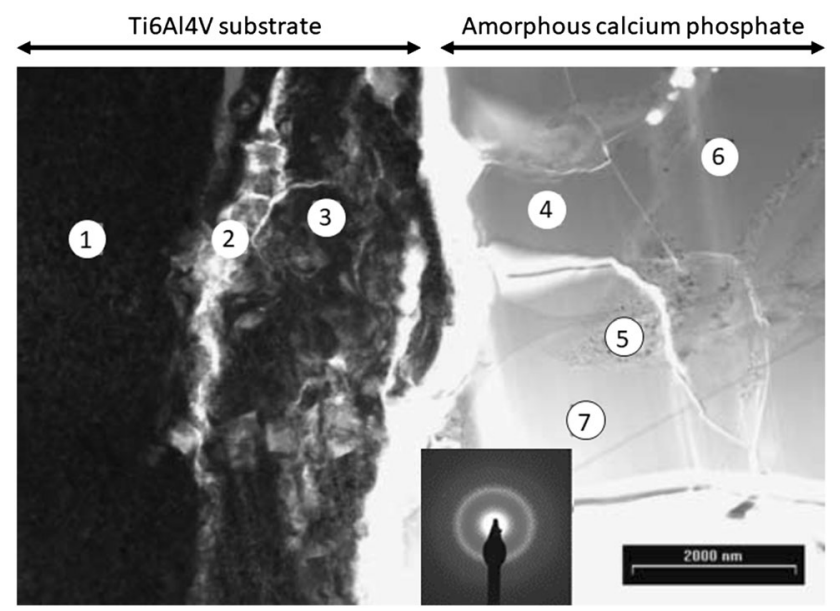

Fig. 7 Scanning transmission electron microscopy (STEM) image of the substrate (left)-coating (right) interface of plasma-sprayed hydroxylapatite. The electron-transparent sample was generated by FIB (focused ion beam) cutting using Ga ions. The inset shows the electron diffraction pattern of ACP, characterized by a diffuse single ring with radius $d=0.809 \mathrm{~nm}$ that suggests short-range order (SRO) configuration corresponding to (010) of hydroxylapatite. 1: Intact Ti6Al4V substrate; 2: Residual alumina grit particles; 3: Ti6Al4V interface damaged by grit blasting; 4: Amorphous calcium phosphate (ACP, $\mathrm{Ca} / \mathrm{P}=1.38)$; 5: Crystalline portlandite, $\mathrm{Ca}(\mathrm{OH})_{2} ; 6$ : Amorphous calcium phosphate $(\mathrm{ACP}, \mathrm{Ca} / \mathrm{P}=1.43)$; 7 : Amorphous calcium phosphate $(\mathrm{ACP}, \mathrm{Ca} / \mathrm{P}=1.32)(\operatorname{Ref} 85)$ decrease to 3 mass\% TTCP, and 0.5 mass\% each of $\beta$-TCP and $\mathrm{CaO}$ at the substrate-coating interface. The balance is thought to consist of amorphous calcium phosphate (ACP) that reaches in excess of $80 \%$ at the substrate-coating interface owing to rapid quenching of the arriving molten droplets (Ref 88). This ACP layer forms immediately adjacent to the metallic substrate (Fig. 7). Figure 6, right, shows that the crystallinity of the hydroxylapatite coating decreases exponentially with depth from about $93 \%$ at the free coating surface to approximately $55 \%$ at the coatingsubstrate interface.

Figure 7 shows a scanning transmission electron microscopy (STEM) image of the cross section of a plasma-sprayed calcium phosphate coating (right, positions 4, 6 and 7) on a Ti6Al4V substrate (left, positions 1 and 3). Owing to the action of alumina grit blasting used to provide a rough substrate surface, the Ti6Al4V underwent heavy damage with fold-over of loosened surface particles (position 3), thereby trapping residual alumina grit particles (position 2). The ACP layer shows an average $\mathrm{Ca} / \mathrm{P}$ ratio of 1.38 (position 4: $\mathrm{Ca} / \mathrm{P}=1.38$; position $6: \mathrm{Ca} / \mathrm{P}=1.43$; position $7: \mathrm{Ca} / \mathrm{P}=1.32$ ). Adjacent to the ACP layer, there is a fully crystalline region of close to stoichiometric HAp (not shown in Fig. 7) with $\mathrm{Ca} / \mathrm{P} \sim 1.67$. Position 5 indicates small crystallites of portlandite, $\mathrm{Ca}(\mathrm{OH})_{2}$, the product of the reaction with atmospheric humidity of $\mathrm{CaO}$ formed according to reactions $4 \mathrm{a}$ and $\mathrm{b}$ (Table 2).

The transformation of ACP to HAp occurs preferentially along cracks suggesting that the crack energy released may be a driving force for the solid-state transformation reaction. The incongruent decomposition rate of HAp during plasma spraying determines the relative amounts of TCP, TTCP and $\mathrm{CaO}$ formed within the coating (Ref 83). A high decomposition rate obtained at high plasma enthalpies leads to large amounts of TCP + TTCP + ACP and effects subsequent decomposition of TTCP into $\mathrm{CaO}+\mathrm{P}_{2} \mathrm{O}_{5}$ (Table 2, reaction $4 \mathrm{~b}$ ). Since the TCP will completely dissolve in the melt, the $\mathrm{Ca} / \mathrm{P}$ ratio of the solidifying melt will eventually approach 1.5. Consequently, on cooling, crystallization of only B-TCP occurs. Conversely, a low decomposition rate achieved at lower plasma enthalpy leads to a substantially reduced amount of $\mathrm{TCP}+\mathrm{TTCP}+\mathrm{ACP}$. Then, the $\mathrm{Ca} / \mathrm{P}$ ratio of the melt will approach 1.67 and, on cooling, HAp with some TTCP and B-TCP will crystallize (Fig. 17, left). This evolutionary sequence has been experimentally confirmed by Gross et al. (Ref 89) who showed that OH-bearing ACP with $\mathrm{Ca} /$ $\mathrm{P}=1.67$ crystallizes on heating to a temperature as low as $510{ }^{\circ} \mathrm{C}$ to form stoichiometric HAp. However, since usually no $\mathrm{OH}^{-}$can be detected in $\mathrm{ACP}$, its crystallization may be associated with formation of $\mathrm{OH}^{-}$by the reaction $\mathrm{O}^{2-}+\mathrm{H}_{2} \mathrm{O} \rightarrow 2 \mathrm{OH}^{-}$(Ref 80 ). The assumed sequence of phase formation is also corroborated by the results of 

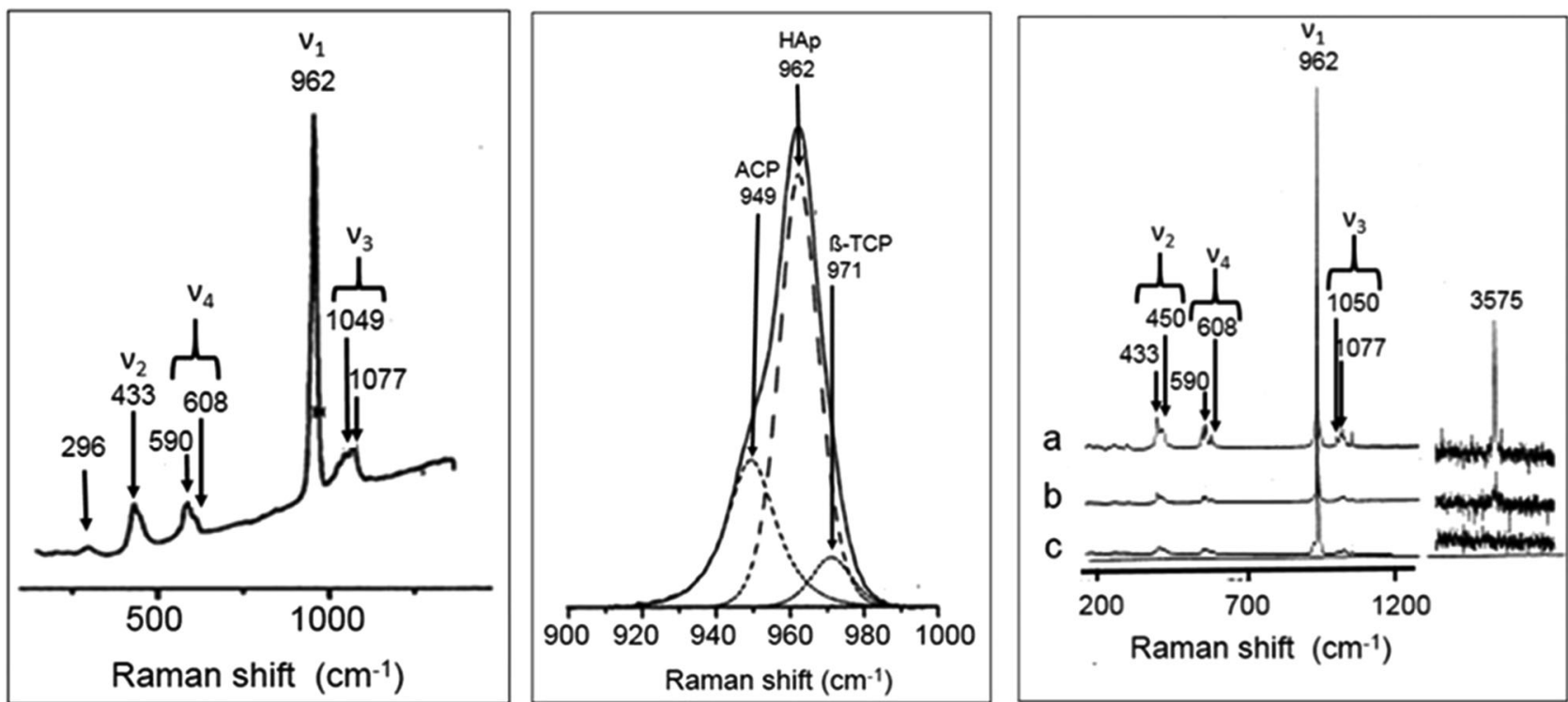

Fig. 8 Left: Laser-Raman spectrum of a plasma-sprayed hydroxylapatite coating showing the four principal vibrational modes of the $\mathrm{PO}_{4}{ }^{3-}$ tetrahedron. Center: The $v_{1}$ Raman mode deconvolved by a Gaussian-Lorentzian fit. The left shoulder at $949 \mathrm{~cm}^{-1}$ may be associated with ACP, the right shoulder at $971 \mathrm{~cm}^{-1}$ originates from B-TCP. Right: Principal Raman spectra of as-received HAp powder

Raman and NMR spectroscopy as shown in the following sections.

\section{Raman Spectroscopy}

Raman microspectroscopy is a valuable tool to obtain information on the distribution of various calcium phosphate phases within plasma-sprayed hydroxylapatite coatings to assess their homogeneity. Indeed, this technique provides unique information on both the microstructure and crystallinity of coatings, being able to distinguish among crystalline phases such as hydroxylapatite, oxyapatite, and tricalcium phosphate, and amorphous (ACP) or short-range-ordered (SRO) calcium phosphates.

Figure 8, left, shows a laser-Raman spectrum $(\lambda=514.6 \mathrm{~nm} ; 5 \mathrm{~mW})$ of the surface of a plasma-sprayed hydroxylapatite coating in the full spectral range between 250 and $1500 \mathrm{~cm}^{-1}$ comprising the four principal vibrational modes of the $\mathrm{PO}_{4}{ }^{3-}$ tetrahedron. These modes consist of (1) the high intensity symmetric stretching mode of the P-O bonds $v_{1}$ at $962 \mathrm{~cm}^{-1}$, (2) the doubly degenerate O-P-O bending mode $v_{2}$ at $433 \mathrm{~cm}^{-1}$, (3) the triply degenerate asymmetric $\mathrm{P}-\mathrm{O}$ stretching mode $v_{3}$ at $1077 \mathrm{~cm}^{-1}$ as well as (4) the triply degenerate O-P-O bending mode $v_{4}$ at $590 \mathrm{~cm}^{-1}$ (Ref 90). These Raman bands deviate in their frequencies somewhat from those reported by Cusco et al. (Ref 91) that were obtained from measurements on phosphate ions in aqueous solution. In (a), HAp powder annealed at $1300{ }^{\circ} \mathrm{C}$ for $3 \mathrm{~h}$ (b) and a plasmasprayed HAp coating on a Ti6Al4V substrate (c). The $\mathrm{OH}$ stretching vibrations at $3575 \mathrm{~cm}^{-1}$ are also shown, attesting to the consecutive loss of $\mathrm{OH}$ during annealing and plasma spraying, respectively (Ref 92)

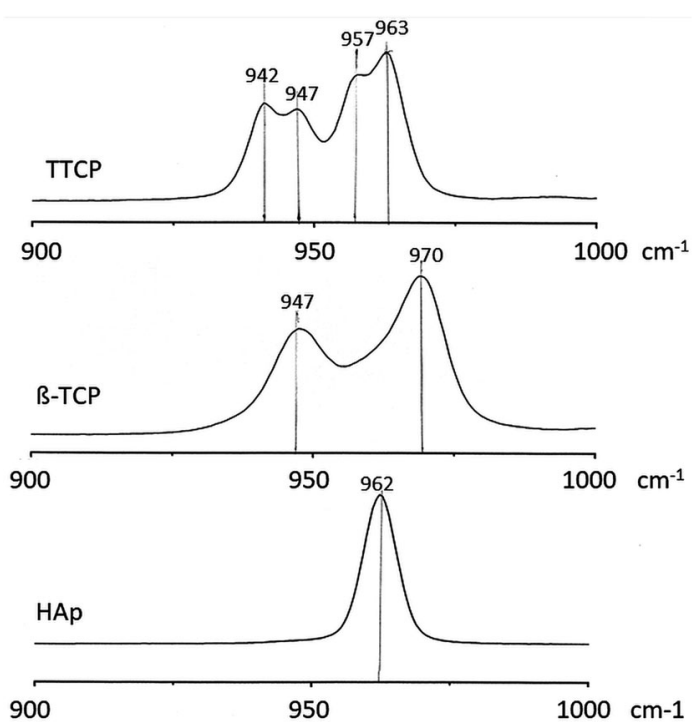

Fig. 9 Standard laser-Raman spectra of tetracalcium phosphate (TTCP), ß-tricalcium phosphate (ß-TCP) and hydroxylapatite (HAp) (Ref 90, 99)

crystals such as hydroxylapatite, the crystal field induces distortion of the $\mathrm{PO}_{4}{ }^{3-}$ tetrahedra, resulting in shifting and splitting of the Raman signals of the normal modes as shown in Fig. 8, left.

Figure 8 center shows that the $v_{1}$ mode of the $\mathrm{PO}_{4}{ }^{3-}$ tetrahedron is composed of a main contribution at $962 \mathrm{~cm}^{-1}$ typical for well-ordered HAp (Ref 91) and 
weaker signals centered on 949 and $971 \mathrm{~cm}^{-1}$ obtained by fitting the composite Raman peak with a Gaussian-Lorentzian function. The signal at $949 \mathrm{~cm}^{-1}$ can be loosely associated with ACP (Ref 93-95) as well as changes of the environment around the orthophosphate tetrahedron caused by $\mathrm{OH}^{-}$vacancies as typical for oxyhydroxylapatite (Ref 90). The vibrational band at $971 \mathrm{~cm}^{-1}$ (Ref 94) may be related to tricalcium phosphate formed during thermal decomposition of oxyapatite (Table 2, step 3). The intensity of the $v_{1}$ vibration, together with the relative intensities of its side peaks, will give information on the degree of ordering of the structure of crystalline hydroxylapatite. Indeed, the intensity ratio $\mathrm{I}_{962} / \Sigma\left(\mathrm{I}_{949}+\mathrm{I}_{971}\right)$ can be considered a crystallinity index that was found to be 1.72 for HAp coatings without a bond coat but 2.52 for HAp coatings with a $\mathrm{TiO}_{2}$ bond coat, confirming the notion that bond coats promote the formation of crystalline HAp at the expense of ACP. The decrease of the intensity of the $\mathrm{OH}$ stretching vibration at $3575 \mathrm{~cm}^{-1}$ from as-received HAp powder (a) to powder annealed at $1300{ }^{\circ} \mathrm{C}$ (b) to a plasmasprayed coating (c) is indicative of the consecutive loss of $\mathrm{OH}$ ions with increased heat treatment (Fig. 8, right).

To determine the extent of thermal decomposition of hydroxylapatite toward tri- and tetracalcium phosphates, comparison with standard Raman spectra obtained from phase-pure tetracalcium phosphate (TTCP), ß-tricalcium

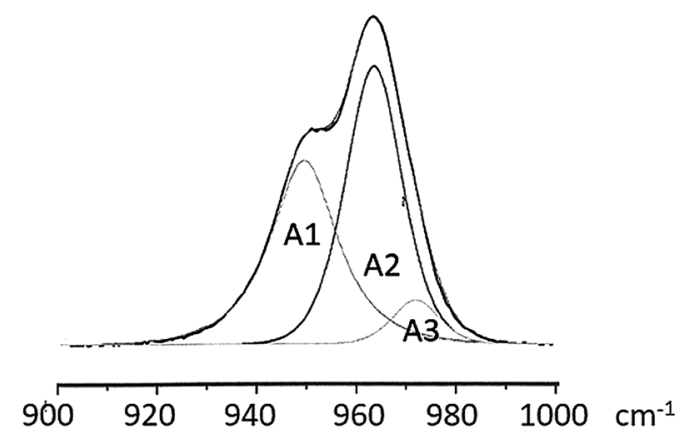

(a)

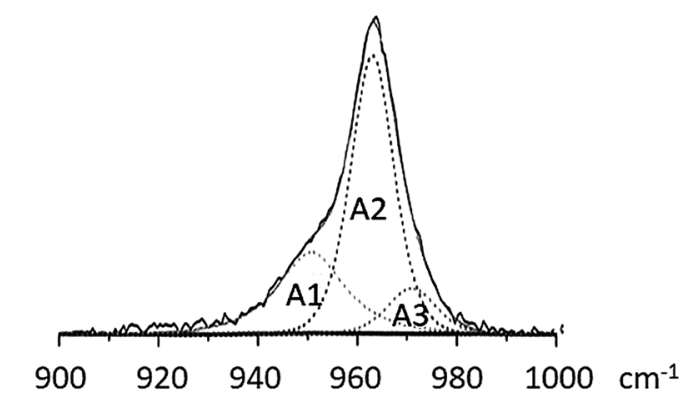

(c)

Fig. 10 Laser-Raman spectra of as-sprayed hydroxylapatite coatings without a bond coat (left column; A as-sprayed; C incubated for 12 weeks in r-SBF) and with a $\mathrm{TiO}_{2}$ bond coat (right column; B as- phosphate (B-TCP) and hydroxylapatite (HAp) can be used (Fig. 9). The Raman spectrum of TTCP shows a bimodal distribution with doublets at 942-947 and $957-963 \mathrm{~cm}^{-1}$ (Ref 96). The spectrum of B-TCP is characterized by two broad Raman bands centered at 947 and $970 \mathrm{~cm}^{-1}$. Finally, the HAp spectrum shows only a single band centered at $962 \mathrm{~cm}^{-1}$. The Raman spectrum of an as-sprayed hydroxylapatite coating without an adhesion-mediating bond coat is shown in Fig. 10(a) that of an as-sprayed hydroxylapatite coating with a $\mathrm{TiO}_{2}$ bond coat is shown in Fig. 10(c). From the appearance of the spectra, it is evident that the presence of a bond coat significantly alters the Raman spectrum, showing predominantly well-crystallized hydroxylapatite (band A2) with concurrent strong suppression of the composite Raman band A1 (TTCP + B$\mathrm{TCP}+\mathbf{A C P}+\mathrm{OHAp})$ centered around $950 \mathrm{~cm}^{-1}$ and also some decrease of the intensity of the band A3 (BTCP + OHAp) centered around $972 \mathrm{~cm}^{-1}$. Similar shifts in Raman band positions have been observed recently by Demnati et al. (Ref 94). The increase in crystallinity of hydroxylapatite in the presence of a bond coat is related to the substantially decreased thermal diffusivity of the bond coat material, allowing the deposited molten splats to solidify more slowly and thus, providing time for nucleation and crystal growth (Ref 97). Incubation of the two types of coating for 12 weeks in r(evised)-SBF (Ref 98)

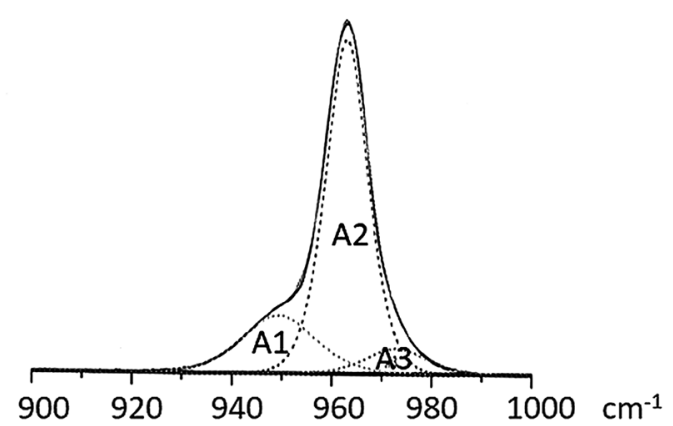

(b)

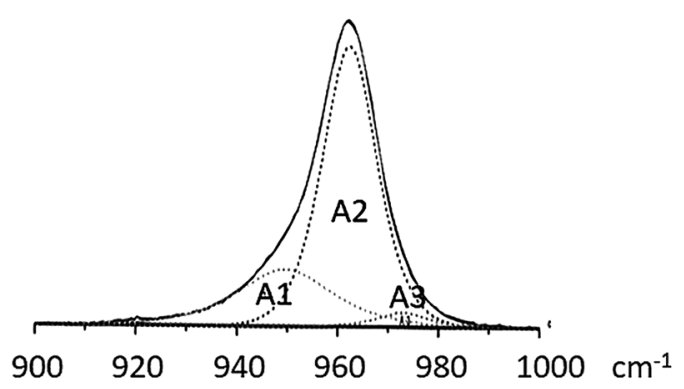

(d)

sprayed; D incubated for 12 weeks in r-SBF). Raman band A1: TTCP + B-TCP + ACP + OHAp, Raman band A2: well-ordered HAp, Raman band A3: B-TCP + OHAp (Ref 99) 
Table 3 Quantitative composition in mass\% of hydroxylapatite coatings without and with a $\mathrm{TiO}_{2}$ bond coat as-sprayed and after incubation in r-SBF for 1 and 12 weeks (based on Raman data) (Ref 99)

\begin{tabular}{lcccccc}
\hline Composite Raman band & \multicolumn{3}{c}{ Without bond coat } & \multicolumn{3}{c}{ With TiO $_{2}$ bond coat } \\
\cline { 2 - 5 } & 0 weeks & 1 week & 12 weeks & 0 weeks & 1 week & 12 weeks \\
\hline A1 (ACP) & 44 & 35 & 22 & 23 & 21 \\
A2 (HAp) & 43 & 53 & 75 & 66 & 70 \\
A3 (B-TCP) & 13 & 12 & 3 & 11 & 9 \\
\hline
\end{tabular}

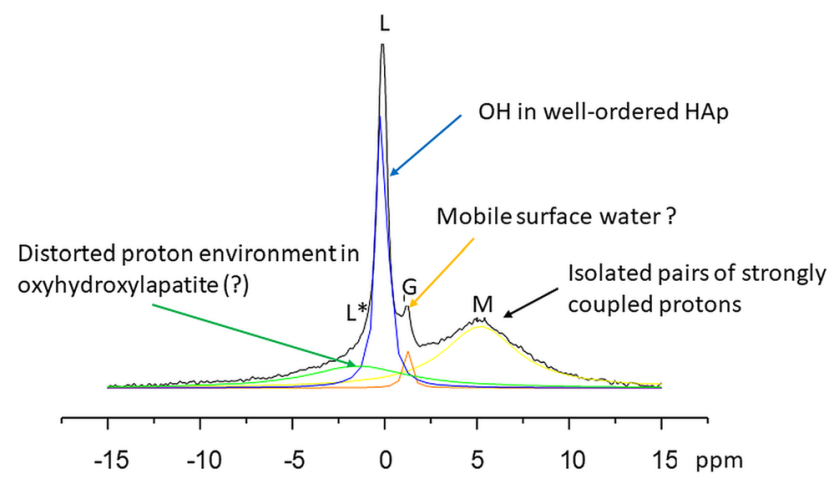

Fig. 11 Proton-MAS NMR spectrum of as-sprayed hydroxylapatite. L highly stoichiometric HAp; L* oxyhydroxylapatite (?), G mobile (free) water, $M$ isolated pairs of strongly coupled protons in HAp channels (Ref 90, 99, 100)

shows that the proportion of HAp in coatings without and with a bond coat increases strongly to 75 and 80 mass $\%$, respectively (Table 3 ). It is significant that in the assprayed state the amount of well-crystallized HAp has increased by $50 \%$ in the presence of a bond coat. Hence, immediately at first contact of the coated implant with body fluid, resorption will commence at a much slower rate, resulting in a significantly more stable situation as far as the integrity of the osseoconductive coating is concerned. More details will be provided in "Interaction of Plasma-Sprayed Hydroxylapatite Coatings with Simulated Body Fluid" section below.

\section{Solid-State Nuclear Magnetic Resonance (NMR) Spectroscopy}

Even more detailed information on the degree of disorder introduced by thermal treatment of hydroxylapatite during plasma spraying can be obtained by solid-state nuclear magnetic resonance (NMR) spectroscopy. The positions and shifts of ${ }^{1} \mathrm{H}$-MAS and ${ }^{31} \mathrm{P}-\mathrm{MAS}$ NMR peaks are indicative of the structural environment of the $\mathrm{PO}_{4}{ }^{3-}$ tetrahedra in calcium orthophosphates and thus, allow distinguishing between dehydroxylation (oxyhydroxylapatite/oxyapatite) and decomposition products (tricalcium phosphate, tetracalcium phosphate) of hydroxylapatite.
Figure 11 and 12 show ${ }^{1} \mathrm{H}-$ and ${ }^{31} \mathrm{P}$ NMR spectra, respectively, of as-sprayed hydroxylapatite (Ref 90, 99, 100). While the ${ }^{1}$ H-MAS NMR spectrum of stoichiometric, highly crystalline hydroxylapatite shows only one single narrow band position at $-0.1 \pm 0.1 \mathrm{ppm}$ (Fig. 11; band L), in plasma-sprayed hydroxylapatite coatings additional non-equivalent bands can be detected at $-1.3 \pm 0.3 \mathrm{ppm}$ (band $\mathrm{L}^{*}$ ) and $+5.2 \pm 0.2 \mathrm{ppm}$ (band $\mathrm{M})$. The main band $\mathrm{L}$ represents the proton band position of crystalline stoichiometric hydroxylapatite, whereas the weak isotropically shifted band $\mathrm{L}^{*}$ can be attributed to protons in distorted HAp short-range ordered (SRO) structures such as oxyhydroxylapatite. The band $\mathrm{M}$ relates to $\mathrm{OH}^{-}$positions missing only one neighboring $\mathrm{OH}^{-}$ion and hence indicates the existence of isolated pairs of strongly coupled protons (Ref 100). This band has been assigned to water molecules existing in the channel structure of HAp (Ref 101, 102). The band $G$ at about +1.3 ppm may belong to free, i.e., mobile water adsorbed at the surface of HAp (Ref 99).

The features of the ${ }^{31} \mathrm{P}-\mathrm{MAS}$ (magic angle spinning) NMR spectrum of plasma-sprayed hydroxylapatite are even more complex and hence, open to discussion. Figure 12 shows the single band position $\mathrm{A}$ at $+2.3 \pm 0.1 \mathrm{ppm}$ of the $\mathrm{PO}_{4}{ }^{3-}$ tetrahedra in well-ordered, highly crystalline hydroxylapatite. In plasma-sprayed hydroxylapatite, several additional non-equivalent band positions can be discerned, neither of which can be unequivocally attributed to the known chemical shifts of thermal decomposition phases such as tricalcium phosphate or tetracalcium phosphate. Instead, they were related to variously distorted $\mathrm{PO}_{4}{ }^{3-}$ groups as follows. Band $\mathrm{D}$ at $+5.0 \pm 0.2 \mathrm{ppm}$ may belong to very strongly distorted $\mathrm{PO}_{4}{ }^{3-}$ groups without associated $\mathrm{OH}^{-}$groups, band $\mathrm{C}$ at $+3.0 \pm 0.2 \mathrm{ppm}$ is thought to be associated with distorted $\mathrm{PO}_{4}{ }^{3-}$ groups with single or paired $\mathrm{OH}^{-}$groups, and band $\mathrm{B}$ at $+1.5 \pm 0.2 \mathrm{ppm}$ has been assigned to a strongly distorted $\mathrm{PO}_{4}{ }^{3-}$ environment without neighboring $\mathrm{OH}^{-}$ (Ref 90, 100).

In addition, 2D-double quantum ${ }^{31} \mathrm{P}-{ }^{1} \mathrm{H}$ cross-polarization heteronuclear correlation (HETCOR) NMR spectra shows more details of the thermal deterioration of 
hydroxylapatite during plasma spraying (Fig. 13, left). The 2D spectrum of the as-sprayed HAp coating is characterized by a rather broad A-L band assigned to more or less stoichiometric hydroxylapatite and three weaker composite NMR bands C-M, B-M and B-N. However, the presence of a $\mathrm{TiO}_{2}$ bond coat substantially affects the 2D-NMR spectra as shown in Fig. 13, right. The central A-L peak is somewhat sharper than that of a coating without a bond coat owing to higher crystallinity and phase purity. There are no C-M and B-N bands, and the much weaker B-M band disappears completely after an incubation time of 4 weeks (not shown) in accord with the notion that the easily soluble distorted structures including oxyhydroxylapatite and oxyapatite will be preferentially removed. Indeed, the incubated coating in the presence of a bond coat consists to more than $90 \%$ of well-ordered, highly crystalline HAp but still contains sizeable amounts of TCP and TTCP after incubation for 12 weeks (Table 4).

The result of quantitative evaluation of the 2D-HETCOR spectra is shown in Table 4. As expected, incubation in r-SBF causes, over time, dissolution of phases characterized by the 'distorted states' 1 and 2 associated with oxyhydroxylapatite, i.e., partially dehydroxylated SROstructured hydroxylapatite as well as dissolution of the thermal decomposition products TTCP and TCP, but to a lesser extent. Concurrently, the relative proportion of crystalline well-ordered hydroxylapatite increases from a low 46 mass $\%$ in an as-sprayed coating to a high 74 mass $\%$ in a coating incubated under physiological conditions in r-SBF for 12 weeks. This nicely confirms the quantitative phase composition obtained from Raman spectroscopy shown above.

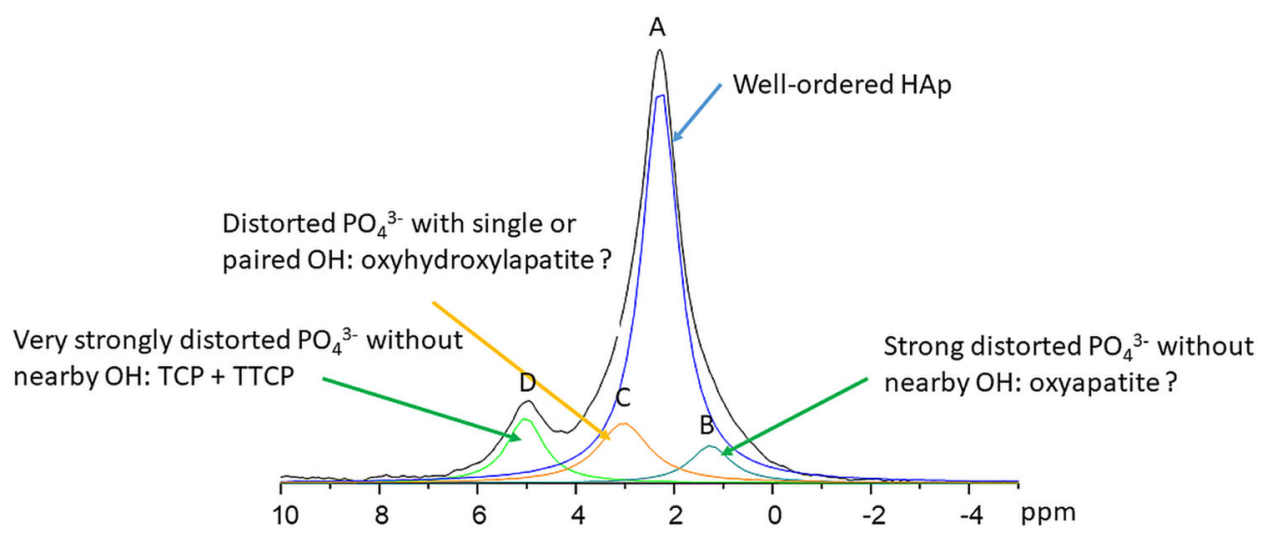

Fig. $12{ }^{31}$ P-MAS NMR spectrum of as-sprayed hydroxylapatite. $A$ orthophosphate moieties in well-ordered HAp, $B$ strongly distorted environment lacking neighboring $\mathrm{OH}$ ions (oxyapatite ?), $C$ distorted

orthophosphate moieties with single (or paired) $\mathrm{OH}$ ions (oxyhydroxylapatite ?), $D$ very strongly distorted orthophosphate moieties without nearby OH ions (TCP, TTCP) (Ref 90, 99, 100)
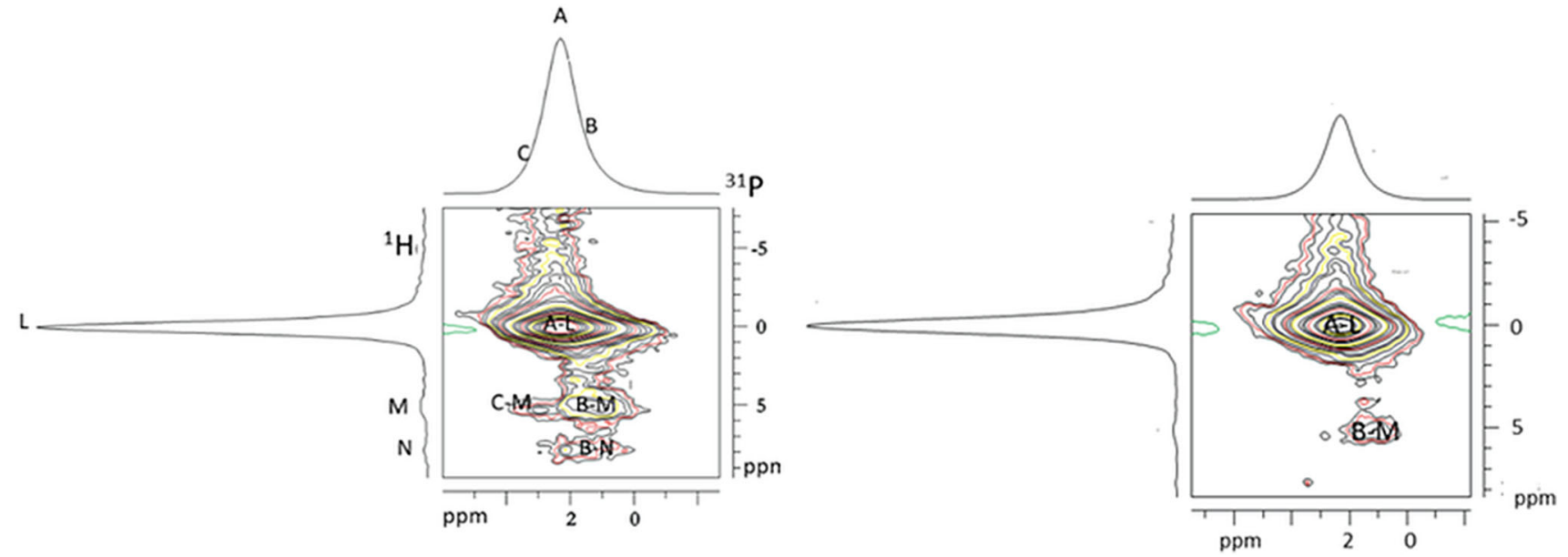

Fig. $132 \mathrm{D}-{ }^{31} \mathrm{P}-{ }^{1} \mathrm{H}$ HETCOR-CP-NMR spectra of a plasma-sprayed hydroxylapatite coating. Left: without a bond coat. Right: with a TiO 2 bond coat of about $15 \mu \mathrm{m}$ thickness (Ref 99) 
Table 4 Composition of hydroxylapatite coatings without and with a $\mathrm{TiO}_{2}$ bond coat in mass\% as-sprayed (0 weeks), and incubated for 1 and 12 weeks in r-SBF (based on NMR data) (Ref 99)
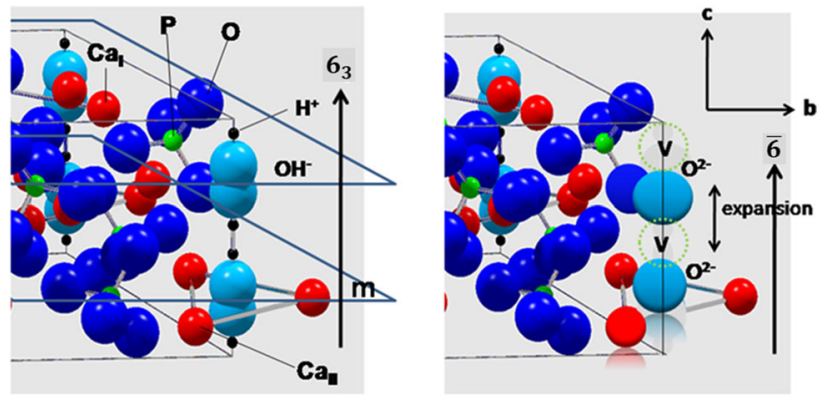

Fig. 14 Left: Ball-and-spoke model of hydroxylapatite with space group $\mathrm{P}_{3} / \mathrm{m}$. The mirror planes $\mathrm{m}$ through $z=1 / 4$ and $3 / 4$ are shown perpendicular to the screw axis $6_{3}$. Right: Hypothetical structure of oxyapatite with lower symmetry $\mathrm{P} \overline{6}$ showing a chain of $\mathrm{O}^{2-}$ ions parallel to the polar hexagonal axis $\overline{6}$ separated by vacancies $\mathrm{V}$

\section{The Oxyapatite Conundrum}

Among the thermally altered calcium phosphate phases observed during plasma spraying of hydroxylapatite, the elusive oxyapatite phase takes on a specific significance. Oxyapatite, $\mathrm{Ca}_{10}\left(\mathrm{PO}_{4}\right)_{6} \mathrm{O}_{x} \square_{x}(\mathrm{OA})$ is the product of complete dehydroxylation of hydroxylapatite and is known to be able to convert back to stoichiometric hydroxylapatite in the presence of water either during cooling of the assprayed coating in moist air or by reaction with ECF in vivo.

The oxyapatite question has a long and colorful but controversial history (Ref 103). Oxyapatite as a stable mineral was first proposed by Voelcker (Ref 104), and this supposedly novel compound was subsequently named voelckerite in his honor by Rogers (Ref 105).

However, the existence of pure oxyapatite stable at ambient conditions was already discredited by Korber and Trömel (Ref 106) and severely questioned by Bredig et al. (Ref 107) who drafted one of the earliest $\mathrm{CaO}-\mathrm{P}_{2} \mathrm{O}_{5}$ phase diagrams in the absence of water. Instead, based on experimental evidence, Bredig et al. were first to propose the existence of 'mixed' apatite, i.e., oxyhydroxylapatite $\mathrm{Ca}_{10}\left(\mathrm{PO}_{4}\right)_{6} \mathrm{X}_{2-2 n} \mathrm{O}_{\mathrm{n}}(\mathrm{X}=\mathrm{OH}, \mathrm{F} ; 0<n<1)$. In addition, they concluded that, for energetic reason, the $\mathrm{X}$ (c-axis channel) position could not be left empty. In particular, by $\mathrm{x}$-ray analysis no superstructures were found that would point to an ordered distribution of $\mathrm{O}^{2-}$ ions in the c-axis channel and associated vacancies. Indeed, a computational investigation (Ref 108) confirmed that formation of oxygen vacancies in the c-axis channels of hydroxylapatite is thermodynamically unfavorable. Nevertheless, despite these thermodynamic constraints, investigations by Alberius-Henning et al. (Ref 109) into the structure of oxyapatite suggested that there exists a linear chain of $\mathrm{O}^{2-}$ ions parallel to the c-axis, each one followed by a vacancy (Fig. 14, right). Apparently, by introduction of oxygen vacancies in the c-channel, the symmetry element $m$ (mirror plane) is lost and the overall crystallographic symmetry lowered from $\mathrm{P}_{3} / m$ to $\mathrm{P} \overline{6}$.

Subsequently, Calderin et al. (Ref 110) modeled the oxyapatite structure by density-functional theory with local-density approximation (DFT-LDA) and first-principles pseudo-potentials. These authors found several DOS in the energy gaps of oxyapatite that are absent in hydroxylapatite. The defect apatite structure appears to be insensitive to the choice of the anion $\left(\mathrm{OH}^{-}, \mathrm{F}^{-}, \mathrm{Cl}^{-}, \mathrm{O}^{2-}\right.$, $\square$ ) in the c-axis column. Attempts to remove the anions by heating revealed that the overall structure remains largely unchanged and at least metastable. Indeed, investigation by Liao et al. (Ref 111) confirmed that during plasma spraying even after a loss as high as $75 \%$ of the $\mathrm{OH}$ group in the c-axis channel, the basic apatite structure will be maintained. However, it is significant that complete loss of $\mathrm{OH}$ was never experimentally observed, meaning that a small amount of $\mathrm{OH}$ needs to be present in the oxyapatite structure to stabilize it.

The detection of oxyapatite by conventional x-ray diffraction is considered problematic (Ref $23,74,84$ ) since the c-axis length of oxyapatite is only marginally larger than that of hydroxylapatite (Ref 112, 113). This accounts for only a small shift of the (002) interplanar spacing toward smaller diffraction angles. Hence, very accurate measurements are required using, for example, single crystal $\mathrm{x}$-ray diffraction by synchrotron radiation or neutron diffraction techniques. The small lattice expansion during dehydroxylation of HAp toward oxyapatite alluded to in Fig. 14, right and Fig. 15, left, is presumably caused by the larger Shannon crystal radius of the $\mathrm{O}^{2-}$ ion (135 pm) compared to that of the $\mathrm{OH}^{-}$ion (118 pm). 

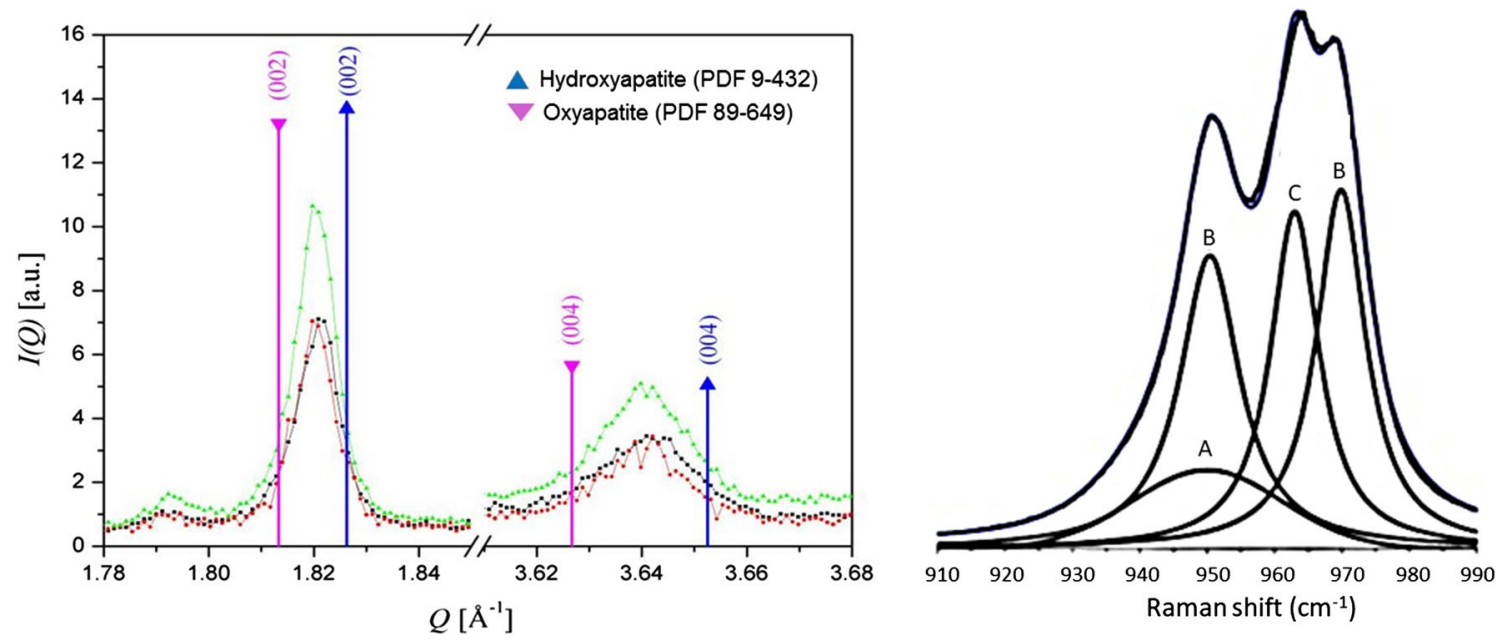

Fig. 15 Left: Scattering vector $Q=4 \pi \sin \Theta / \lambda$ of synchrotron radiation diffraction profiles of three as-sprayed hydroxylapatite coatings showing the vicinities of the (002) and (004) interplanar spacings of hydroxyapatite and oxyapatite (Ref 114). Right: Gaussian-Lorentzian deconvolution of the $v_{1}\left(\mathrm{PO}_{4}\right)$ Raman stretching domain of a lowenergy plasma-sprayed HAp coating. $A$ amorphous calcium phosphate ACP, $B$ oxyapatite, $C$ hydroxylapatite (Ref 116). (C) With permission by Elsevier

the latter to ß-TCP (see Fig. 8, center; Fig. 9). Hence, more sophisticated surface analytical methods must be employed to establish (or refute) the real existence of oxyapatite.

In conclusion, it is still not clear whether oxyapatite can be counted among the (meta)stable phases participating in the complex conversion sequence from ACP to biological apatite during osseoconduction processes or whether it is just an ephemeral intermediate of no consequence (Ref 117).

\section{Interaction of Plasma-Sprayed Hydroxylapatite Coatings with Simulated Body Fluid}

Incubation of hydroxylapatite in simulated body fluids (SBFs) resembling the composition of extracellular fluid (ECF) is a generally applied fingerprint technique to determine the potential biocompatibility of biomedical coatings. The observation that this treatment results frequently in precipitation of bone-like, i.e., Ca-deficient defect apatite is taken by many authors as a strong sign of osseoconductivity. This, however, is in error as such precipitation is only a necessary but not a sufficient precondition of osseoconductivity, the establishment of which requires detailed study of cell viability and proliferation as well as confirmation of upregulation of bone growth proteins including osteocalcin (OC) and alkaline phosphatase (ALP) levels.

Amorphous calcium phosphate (ACP), thermal decomposition products such as $\beta$-tricalcium phosphate ( $B-\mathrm{TCP})$, tetracalcium phosphate (TTCP) and calcium oxide $(\mathrm{CaO})$ as well as the dehydroxylation products oxyhydroxylapatite 
(OHAp) and/or oxyapatite (OA) show enhanced solubility in human extracellular fluid (hECF) and simulated body fluid (SBF) that follow the order (Ref 118)

$$
\begin{aligned}
\mathrm{CaO} & \gg \beta \text {-TCP }>\text { ACP }>\text { TTCP }>\text { OHAp/OA } \\
& \gg \text { HAp. }
\end{aligned}
$$

In contrast, pure and well-crystallized hydroxylapatite is remarkably stable in the presence of aqueous solutions under standard condition, showing a solubility product $K_{\text {ip }}=\left[\mathrm{Ca}^{2+}\right]^{5}\left[\mathrm{PO}_{4}{ }^{3-}\right]^{3}\left[\mathrm{OH}^{-}\right]=2.27 \times 10^{-58}(\operatorname{Ref} 119)$. Moderately enhanced levels of $\mathrm{Ca}^{2+}$ and $\mathrm{HPO}_{4}{ }^{2-}$ ions released to the biofluid-occupied space at the interface implant-tissue are required for bone remodeling (Ref 120). However, excessive amounts of these ions released from the readily dissolving decomposition products of HAp drive up the local $\mathrm{pH}$ values with possibly cytotoxic effects on living bone cells (Ref 121, 122). Consequently, release of high concentrations of ions from dissolving calcium phosphate phases must be kept at bay. This can be done by several strategies aimed at optimizing the amount of wellcrystallized HA in the as-sprayed coating, including optimizing the set of plasma spray parameters that significantly influence the plasma enthalpy and in turn control the thermal history of HAp (see for example Ref 63). In addition, bioinert bond coats such as $\mathrm{TiO}_{2}$ or $\mathrm{ZrO}_{2}$ appear to improve substantially the adhesion between HAp coating and metal substrate (Ref 123,124) and, in addition, act as thermal barriers that may aid enhanced crystallization of HAp at the expense of ACP (see Fig. 10b).

Figure 16 displays cross-sectional SEM backscattered images of an as-sprayed HAp coating with a $\mathrm{TiO}_{2}$ bond coat (a) and a coating incubated for 56 days in protein-free simulated body fluid (b) (Ref 86). After incubation, pronounced zonation has developed with an inner zone of rather homogenous hydroxylapatite and oxyhydroxylapatite/oxyapatite, respectively, with a $\mathrm{Ca} / \mathrm{P}$ ratio between 1.60 and 1.64 (zone 1), typical for near-stoichiometric hydroxylapatite formed adjacent to the Ti6Al4V substrate and the $\mathrm{TiO}_{2}$ bond coat, respectively. This is followed by a layered succession of $\mathrm{Ca}$-deficient apatite with a $\mathrm{Ca} / \mathrm{P}$ ratio of around 1.5 (zone 2), and an outer layer of newly precipitated crystalline Ca-deficient defect ('bone-like') apatite with $\mathrm{Ca} / \mathrm{P} \sim 1.4$ (zone 3 ). As further revealed by cathodoluminescence imaging (Fig. 5, right), the inner coating layer is interspersed with many patchy areas of amorphous calcium phosphate (ACP) accounting for the low integrated $\mathrm{Ca} / \mathrm{P}$ ratio (1.60) measured by EDX. This zoning is reminiscent of diffusion-controlled zoning in gels, a mechanism typical of a dissolution-precipitation sequence thought to govern the transformation of ACP to crystalline calcium phosphate phases.

As far as biomedical and mechanical behavior is concerned, ACP appears to be Janus-faced. On the one hand, its presence increases alkaline phosphatase activity, thus enhancing cell proliferation and adhesion. On the other hand, it provides a path of least energy parallel to the implant surface that may promote coating delamination. It transforms on contact with simulated body fluid and extracellular fluid, respectively, to crystalline phases, presumably via progressive hydrolysis of $\mathrm{PO}_{4}{ }^{3-}$ groups. This transformation occurs predominately along cracks and fissures in the coatings. Figure 17, left, shows that the transformation front sweeps through the ACP phase, leaving in its wake a body of well-crystallized hydroxylapatite as shown by its electron diffraction pattern (inset, top right).

Electron diffraction pattern of the well-crystallized (porous) hydroxylapatite reveals interplanar spacings of (002) at $0.336 \mathrm{~nm},(210)$ at $0.306 \mathrm{~nm}$, and (112) at $0.277 \mathrm{~nm}$.

At the leading edge of the transformation front, crystalline areas of $\beta$-TCP and TTCP appear (Fig. 17, left: insets, top left and center left; Fig. 17, right) as identified by their electron diffraction pattern (Table 5 ). These phases were presumably formed already during coating deposition according to reaction 3 shown in Table 2 (see also Ref 70). The thin line crossing Fig. 17, right, is due to radiation damage within the scanning transmission electron microscope.

The electron diffraction pattern of the pristine ACP ahead of the transformation front is characterized by a
Fig. 16 Cross sections of plasma-sprayed hydroxylapatite coating layers (right) on Ti6Al4V substrates (left). (a) As-sprayed hydroxylapatite coating together with a $\mathrm{TiO}_{2}$ bond coat (center). (b) Coating incubated for 56 days in protein-free simulated body fluid (Ref 86)

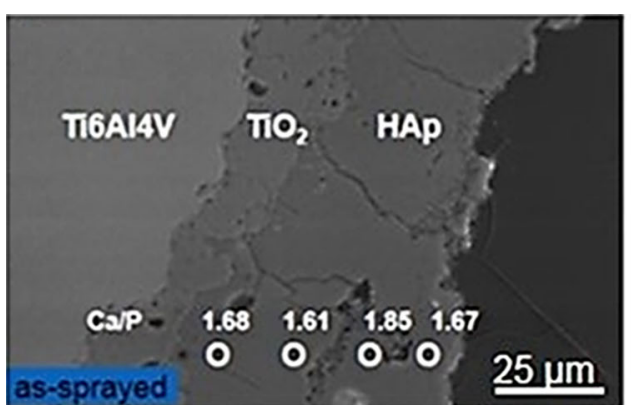

(a)

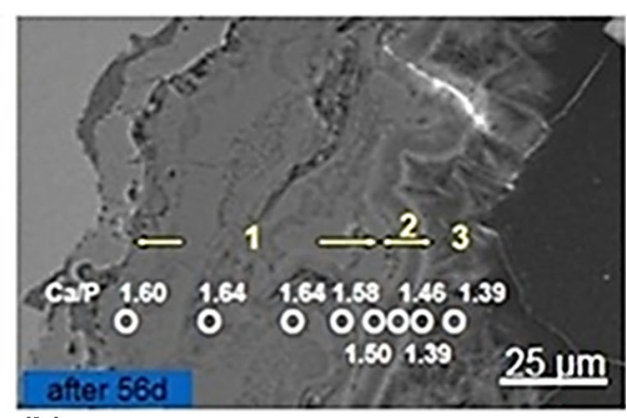

(b) 


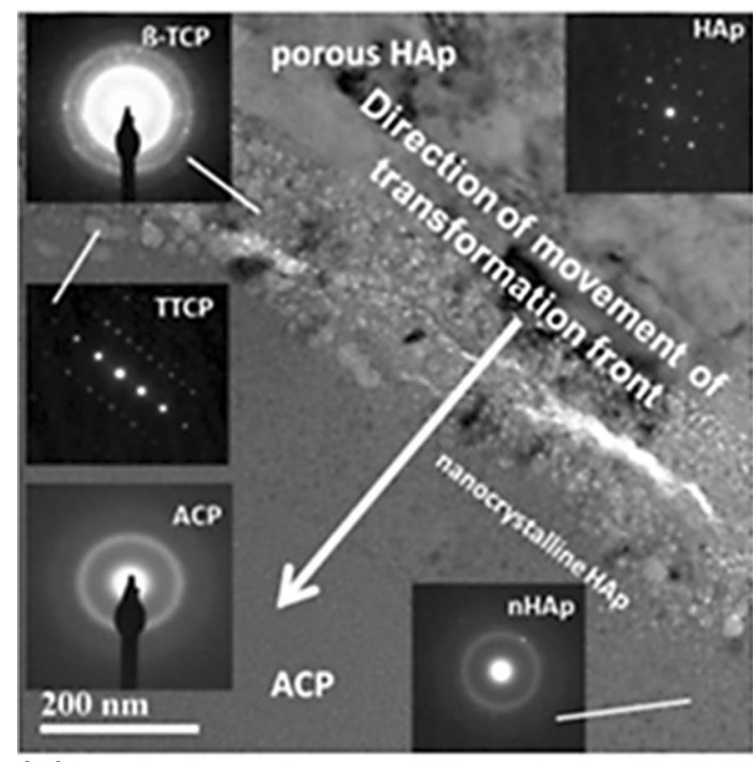

(a)

Fig. 17 Left: Scanning transmission electron microscope (STEM) image of the transformation of ACP to crystalline phases during contact with simulated body fluid (r-SBF) for 1 week. At the trailing edge of the transformation front, well-crystallized HAp prevails,

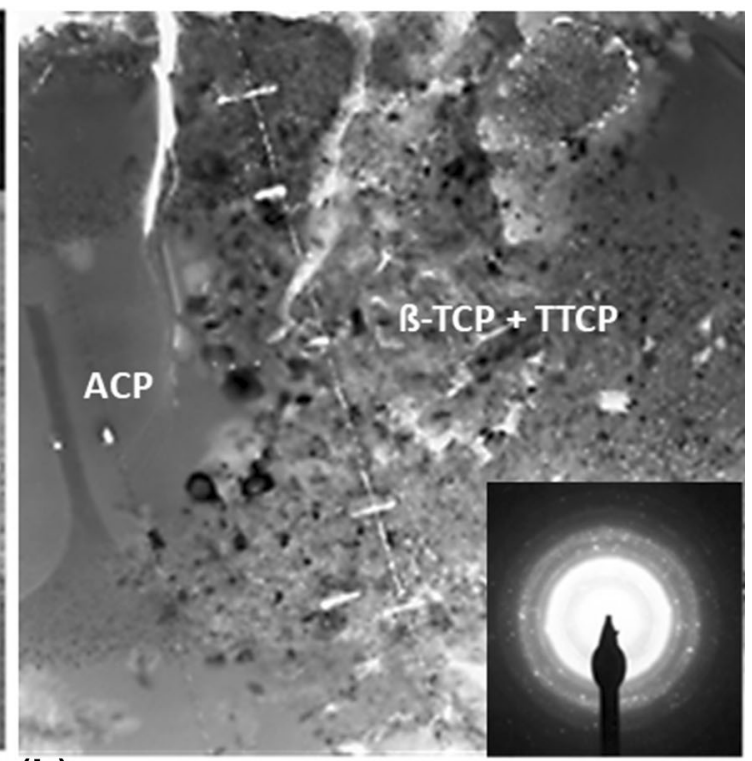

(b)

whereas at the leading edge nano-crystalline HAp is formed. Right: Recrystallization of ACP to form B-TCP + TTCP. Inset: Electron diffraction pattern (Table 5) (Ref 85)
Table 5 Interplanar spacings of B-TCP and TTCP formed during recrystallization of ACP (Ref 85)

\begin{tabular}{lcc}
\hline$d(h l k)$ (measured) & B-TCP (ICDD-PDF 04-014-2292) & TTCP (ICDD-PDF 00-025-1137) \\
\hline 0.805 & $0.814(012)$ & $0.702^{*}(100)$ \\
0.717 & $0.415(018)$ & \\
0.411 & $0.346(1010)$ & $0.351(200)$ \\
0.358 & $0.321(214)$ & $0.289(\overline{1} 03)$ \\
0.319 & & \\
0.290 & $0.288(0210)$ & \\
0.287 & $0.252(2110)$ & \\
0.251 & & \\
\hline
\end{tabular}

*Forbidden reflexion diffuse single ring with $d=0.809 \mathrm{~nm}$, (Fig. 17, left; inset at lower left) corresponding to (100) of hydroxylapatite, a face with minimum specific free surface energy (Ref 125). The hexagonal prisms $\{100\}$ are indeed the morphologically dominant crystal faces of hydroxylapatite with $\mathrm{P}_{3} / \mathrm{m}$ symmetry as they are F-faces (Ref 126) with a maximum number of periodic bond chain $(\mathrm{PBC})$ vectors parallel to the zone axis of these faces. The main $\mathrm{PBC}$ vectors of the apatite structure are $\langle 001\rangle,\langle 100\rangle$ and $\langle 101\rangle$, and the six Ca- $\mathrm{PO}_{4}$ bonds of different lengths and the $\mathrm{Ca}-\mathrm{OH}$ bonds of identical lengths have widely varying surface energies of 2431 and $1269 \mathrm{~kJ} / \mathrm{mole}$, respectively (Ref 127). Apparently, in the SRO structure of ACP, these periodic bond chains are already present and govern the orientation of the Posner's clusters, providing a strong crystallographic control of the transformation process.
Quantitative phase analyses based on x-ray diffraction (XRD) with Rietveld refinement revealed that the $\mathrm{CaO}, \beta$ TCP and TTCP contents decrease with increasing incubation time in r-SBF up to 12 weeks (Fig. 18). The parameters applied to deposit the coating were: plasma power $32 \mathrm{~kW}$, argon flow rate $45 \mathrm{slmp}$, hydrogen flow rate $6.5 \mathrm{slpm}$, powder carrier gas flow rate $5 \mathrm{slpm}$, translation speed $6 \mathrm{~m} / \mathrm{min}$, spray distance $90 \mathrm{~mm}$. After incubation beyond 12 weeks, the approximately $150-\mu \mathrm{m}$-thick coating was found to contain only HAp and some amorphous and/ or SRO phases as ascertained by the pronounced elevated background between about $25^{\circ}$ and $35^{\circ} 2 \Theta$ with a centroid value of $32^{\circ} 2 \Theta$ that corresponds to (300), the lattice plane with maximum intensity in the XRD pattern (ICDD-PDF 00-009-0432).

Addition to the powdered samples of an internal $\mathrm{Al}_{2} \mathrm{O}_{3}$ standard allowed determining quantitatively the amount of 
'amorphous' phase(s) that might be comprised of 'ACP' and the distorted SRO structures (oxyhydroxylapatite/ oxyapatite) found by NMR analysis (Table 4). The quantitative XRD results of the as-sprayed and incubated coatings with a bond coat are in general accord with the laser-Raman and NMR results (cp. Tables 3 and 4). Table 6 shows the phase content obtained by XRD compared to the HAp content determined by Raman and NMR spectroscopies. While the latter data are surprisingly well correlated that also holds for the XRD data of the assprayed sample with a bond coat, there is a clear deviation for the as-sprayed sample without a bond coat. This deviation is rooted in the very different physical processes underlying the analytical procedures involved, including the influence imposed by differing signal acquisition depths.

The loss of $\mathrm{OH}^{-}$groups during plasma spraying and the incorporation during incubation of $\mathrm{OH}^{-}$from water into the lattice of OHAp to reform HAp are reversible processes. Weng et al. (Ref 128) pointed out the essential role water is playing in the conversion process from ACP to

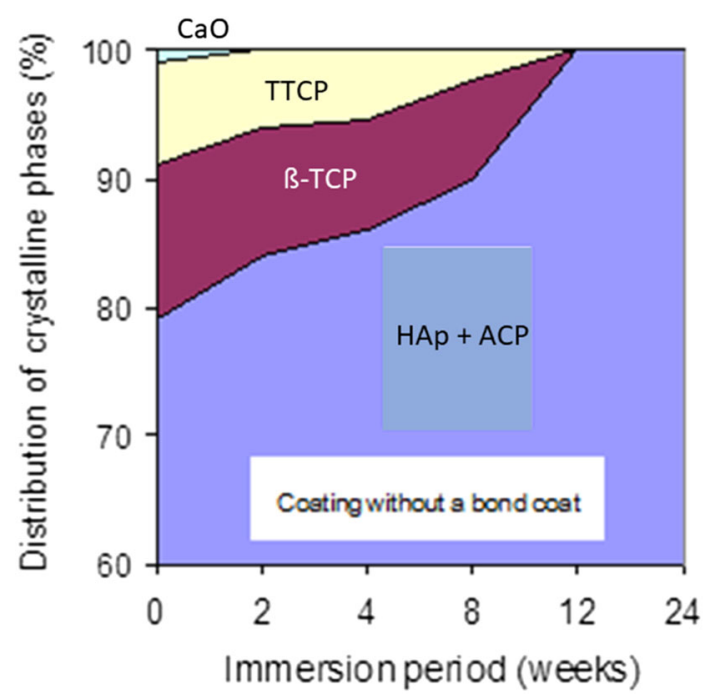

Fig. 18 Quantitative XRD determination of the phase content of a plasma-sprayed hydroxylapatite coating incubated in simulated body fluid (r-SBF) (Ref 90) crystalline hydroxylapatite in plasma-sprayed coatings. According to these authors, the global increase in crystalline HAp is not the result of removal of ACP by dissolution but the consequence of the reconstruction of decomposition products such as TCP, TTCP and amorphous phases toward crystalline HAp. Moreover, the water molecules also combine with oxyhydroxylapatite, so that the $\mathrm{OH}^{-}$groups re-occupy the lattice vacancies at missing $\mathrm{OH}^{-}$sites. All these processes lead to a strong increase of the amount of HAp in plasma-sprayed coatings subjected to incubation in SBF in vitro (Table 6) as well as on contact with ECF in vivo.

\section{Conclusion and Implications}

Deposition of hydroxylapatite coatings by atmospheric plasma spraying is a mature and well research-supported technique to coat the metallic stems of hip endoprostheses and the roots of dental implants. Thus, HAp coatings are a reliable means to achieve lasting osseointegration and long-term in vivo survival of implants, provided that certain requirements are met. These requirements include appropriate implant design selection, the presence of sound bearing surfaces, adequate bone quality according to the patient's age and life expectancy, in particular sufficient bone density, as well as superior surgical skill of the medical operation team. It ought to be mentioned that recently the definition of osseointegration has gone through a paradigmatic shift. Whereas the original definition implied a direct contact between implant materials and bone without any intermediate soft tissue layer, today there is emphasis on osseointegration as a foreign body reaction whereby interfacial bone is formed as a defense reaction to shield off the implant from tissue (Ref 129).

However, despite the clinical success of HAp-coated implants, today implantology appears to have reached a limit of the current medical practice that emphasizes replacement of tissue by a predominantly materials science-based approach (Ref 2). Consequently, novel developments are in the wings that include biologically inspired third-generation biomaterials that concentrate on repair and
Table 6 Quantitative composition in mass\% of hydroxylapatite coatings without and with a $\mathrm{TiO}_{2}$ bond coat after incubation in $\mathrm{r}-\mathrm{SBF}$ for 0,1 and 12 weeks obtained by different surface analytical methods (Ref 99)

\begin{tabular}{|c|c|c|c|c|c|c|}
\hline \multirow[t]{2}{*}{ Analytical method } & \multicolumn{3}{|c|}{ Without bond coat } & \multicolumn{3}{|c|}{ With $\mathrm{TiO}_{2}$ bond coat } \\
\hline & 0 weeks & 1 week & 12 weeks & 0 weeks & 1 week & 12 weeks \\
\hline HAp (XRD) & $65(a)$ & 75 & 73 & 68 & 71 & 70 \\
\hline "Distorted phases" (XRD) & 35 & 25 & 27 & 32 & 29 & 30 \\
\hline HAp (Raman) (Table 2) & 43 & 53 & 75 & 66 & 70 & 80 \\
\hline HAp (NMR) (Table 3) & 46 & 68 & 74 & 63 & 81 & 92 \\
\hline
\end{tabular}

(a) $\mathrm{XRD}$ data $\pm 5 \%( \pm \sigma)$ 
regeneration of damaged or lost tissue on a molecular scale through functionalization of the surfaces of bioceramics or biopolymers by osseoinductive biological agents such as bone morphogenetic proteins or other non-collagenous proteins (Ref 130).

The interplay among numerous plasma spray parameters introduces complexity of a high degree in terms of phase composition, phase distribution, porosity, and microstructure of HAp coatings. Interaction of the surface of plasmasprayed HAp coatings with simulated body fluid resembling the composition of ECF results in preferential dissolution of easily soluble phases and, most importantly, transformation of amorphous calcium phosphate (ACP) to Ca-deficient disordered HAp akin to biological bone-like apatite. Hence, to achieve coatings with superior functionality, during the past decades many attempts have been made to optimize essential properties of osseoconductive bioceramic coatings. These properties include coating thickness, phase composition, crystallinity, porosity, micro- and nano-roughness of coating surfaces, coating adhesion and cohesion, and residual coating stresses. In particular, maintenance of phase composition at values imposed by national and international norms, and control of coating porosity by implementing novel deposition techniques such as suspension (SPS) or solution precursor plasma spraying (SPPS) are fertile development areas. In the end, careful engineering of hydroxylapatite coatings by appropriately adjusting and fine-tuning of plasma spray parameters will ensure deposition of coatings with optimum mechanical, microstructural, chemical, and biological properties (Ref 15-20).

\section{Glossary}

Alkaline phosphatase (ALP)

Arthroplasty

Alveolar ridge

Angioplasty

Bioactivity
Any of the phosphatases that are optimally active in alkaline medium; measure of bone cell growth and bone rebuilding. Apart from its role in normal bone mineralization, the other functions of ALP remain obscure Operative formation or restoration of a joint

Bony ridge or raised thickened border on each side of the upper or lower jaw that contains the sockets of the teeth

Surgical repair or recanalization of a blood vessel

Having an effect on a living organism
Biocompatibility

Bone growth factors

Bone sialoproteins

Callus

Chitosan

Chondrocyte

Chondroitin sulfate

Collagen

Condyle

Connective tissue
Compatibility with living tissue or a living system by not being toxic, injurious, or physiologically reactive and not causing immunological rejection

Bone growth factors include, among others, insulin-like growth factor-1 (IGF-1), insulin-like growth factor-2 (IGF-2), transforming growth factor beta (TGF- $\beta$ ), fibroblast growth factors (FGFs), and bone morphogenetic proteins (BMPs)

They constitute the largest number of non-collagenous proteins (see below). They include serum albumin and some immunoglobulins. Their function is unknown

A mass of exudate and connective tissue that forms around a break in a bone and is converted into bone in healing

A linear polysaccharide composed of d-glucosamine and $\mathrm{N}$-acetyl-dglucosamine. It is produced by treating the chitin shells of shrimp and other crustaceans with sodium hydroxide

A cartilage cell

A glycosaminoglycan (see below) found in cartilage, bone, blood vessels and connective tissues The main structural family of protein in the extracellular matrix, making up from 25 to $35 \%$ of the whole-body protein content. Collagen consists of amino acids wound together to form triplehelices to form elongated fibrils. Collagen I forms in combination with hydroxylapatite the substance of bone

The round prominence at the end of a bone, most often part of a joint that articulates with another bone One of the four basic types of animal tissue, along with epithelial tissue, muscle tissue, and nervous tissue 
Cortical bone

Cytokine

Endochondral

Extracellular fluid (ECF)

Extracellular matrix

Femur

Glycosaminoglycans
The hard outer layer of bones is composed of cortical bone also called compact bone being much denser than cancellous bone. It forms the hard exterior (cortex) of bones. The cortical bone gives bone its smooth and solid appearance, and accounts for $80 \%$ of the total bone mass of an adult human skeleton

Any of a class of immunoregulatory proteins that are secreted by cells especially of the immune system. Cytokines may include chemokines, interferons, interleukins, lymphokines, and tumor necrosis factors but generally not hormones or growth factors

Endochondral ossification takes place from centers arising in cartilage and involves deposition of lime salts in the cartilage matrix followed by secondary absorption and replacement by true bony tissue

Body fluid outside the cells. The ECF has two components-plasma and lymph as a delivery system, and interstitial fluid for water and solute exchange with the cells

A collection of extracellular molecules secreted by support cells that provides structural and biochemical support to the surrounding cells

Thigh bone. The head of the femur articulates with the acetabulum in the pelvic bone forming the hip joint, while the distal part of the femur (condyle) articulates with the tibia and kneecap forming the knee joint. By most measures the femur is the strongest and longest bone in the human body

Long unbranched polysaccharides consisting of a repeating disaccharide unit. Prominent glycosaminoglycans are heparin, chondroitin sulfate, and hyaluronic acid
Harris hip score

Haversian canal

Hyaluronic acid

Matrix protein

Matrix vesicle

Mesenchymal precursor cells

Neointimal

hyperplasia
Method to assess the results of hip surgery, intended to evaluate various hip disabilities and methods of treatment in an adult population

A series of microscopic tubes in the outermost region of cortical bone that allow blood vessels and nerves to travel through them

An anionic, non-sulfated glycosaminoglycan (see above) distributed widely throughout connective, epithelial, and neural tissues. One of the chief components of the extracellular matrix, it contributes significantly to cell proliferation and migration Large molecules tightly bound to form extensive networks of insoluble fibers. These proteins are of two general types, structural and adhesive. The structural proteins, collagen and elastin, are the dominant matrix proteins. At least 10 different types of collagen are present in various tissues. The most common type is collagen I Hydroxylapatite-containing, membrane-enclosed vesicles secreted by osteoblasts, odontoblasts, and some chondrocytes. They are believed to serve as nucleation foci for the mineralization process in bone, dentin, and calcified cartilage Pluripotent stromal cells that can differentiate into a variety of cell types, including osteoblasts (bone cells), chondrocytes (cartilage cells), and myocytes (muscle cells) Proliferation and migration of vascular smooth muscle cells primarily in the tunica intima, resulting in the thickening of arterial walls and decreased arterial lumen space. Neointimal hyperplasia is the major cause of restenosis after percutaneous coronary interventions such as stenting or angioplasty 
Non-collagenous proteins

Odontoblast

Osseoconduction

Osseoinduction

Osseoprogenitor cells

Osteoblast

Osteocalcin (OC)
Non-collagenous components, include proteoglycans (see below) and several glycoproteins such as osteocalcin, osteonectin, and the SIBLING proteins such as osteopontin, bone sialoprotein, and others

A cell that is part of the outer surface of the dental pulp, and whose biological function is formation of dentin, the substance beneath the tooth enamel on the crown and the cementum on the root

The ability of a biomaterial to support the ingrowth of bone cells, blood capillaries, and perivascular tissue into the operation-induced gap between implant body and existing cortical bone bed

The ability to transform undifferentiated mesenchymal precursor stem cells into osseoprogenitor cells that precede endochondral ossification (see above)

Stem cells of bone that eventually form osteoblasts. Osseoprogenitor cells are derived from primitive mesenchymal cells. They form a population of stem cells that can differentiate into the more specialized bone-forming cells such as osteoblasts and osteocytes Cells with a single nucleus that synthesize bone. Osteoblasts function in groups of connected cells. Individual cells cannot generate bone

Non-collagenous GLa (glutamic) protein synthesized by osteoblasts. It is often used as a marker for the bone formation process. Higher osteocalcin levels in serum are relatively well correlated with increases in bone mineral density (BMD). Hence, osteocalcin can be used as a preliminary biomarker on the effectiveness of a given drug on bone formation
Osteocyte

Osteon

Osteonectin $(\mathrm{ON})$

Osteopontin (OPN)

Phosphatidylserine

Proteoglycans
An osteoblast that has become embedded within the bone matrix, occupying a bone lacuna, and sending, through the canaliculi, cytoplasmic processes that connect with other osteocytes in developing bone. The osteocyte is an important regulator of bone mass and a key endocrine regulator of phosphate metabolism

A group of organized osteoblasts together with the bone made by a unit of cells

Non-collagenous phosphoprotein found in bone. It binds collagen I and hydroxylapatite and thus, plays a crucial role in bone mineralization

Osteopontin is a phosphorylated acidic glycoprotein that functions as an immune modulator, and affects wound healing. In contrast to its restricted distribution in normal tissue, OPN is strikingly upregulated at sites of inflammation and tissue remodeling A phospholipid component of the cell membrane. It plays a key role in cell cycle signaling, specifically in relationship to apoptosis, the process of programmed cell death the biochemical events of which lead to characteristic morphological cell changes and death

Non-collagenous proteins with a small protein core and up to two chondroitin sulfate (see above) chains attached. Proteoglycans are a major component of the extracellular matrix (see above). Here, they form large complexes, both to other proteoglycans such as hyaluronic acid, and to fibrous matrix proteins such as collagen. The combination of proteoglycans and collagen form cartilage. Their role in bone mineralization is unclear 
Restenosis

Simulated body fluid (SBF)

Spongiosa

Thrombus
The recurrence of stenosis, a narrowing of a blood vessel that leads to restricted blood flow A solution with an ionic concentration close to that of human blood plasma, kept under mild conditions of $\mathrm{pH}$ and identical physiological temperature. Immersion of biomaterials in SBF is a cofactor to determine bioactivity

Cancellous or trabecular bone typically found at the ends of long bones, near joints, and in the interior of vertebrae The final product of the blood coagulation step in hemostasis. There are two components to a thrombus: aggregated platelets and red blood cells that form a plug with a mesh of cross-linked fibrin protein

\section{References}

1. M. Navarro, A. Michiardi, O. Castaño, and J.A. Planell, Biomaterials in Orthopaedics, J. R. Soc. Interface, 2008, 5(27), p 1137-1158

2. H.F. Hildebrand, N. Blanchemain, G. Mayer, F. Chai, M. Lefebvre, and F. Boschin, Surface Coatings for Biological Activation and Functionalization of Medical Devices, Surf. Coat. Technol., 2006, 200, p 6318-6324

3. D.W. Zhao, F. Witte, F.Q. Lu, J.L. Wang, J.L. Li, and L. Qin, Current Status on Clinical Application of Magnesium-Based Orthopedic Implants: A Review from Clinical Translational Perspective, Biomaterials, 2016, 112, p 287-302

4. J.D. Pasteris, A Mineralogical View of Apatite Biomaterials, Am. Mineral., 2016, 101(12), p 2594-2610

5. C. Rey, C. Combes, C. Drouet, and M.J. Glimcher, Bone Mineral: Update on Chemical Composition and Structure, Osteoporosis Int., 2009, 20(6), p 1013-1021

6. R.M. Wilson, J.C. Elliot, S.E.P. Dowker, and L.M. RodriguezLorenzo, Rietveld Refinements and Spectroscopic Studies of the Structure of Ca-Deficient Apatite, Biomaterials, 2005, 26(11), p $1317-1327$

7. J.D. Pasteris, B. Wopenka, and E. Valsami-Jones, Bone and Tooth Mineralization: Why Apatite? Elements, 2008, 4, p 97104

8. R.B. Heimann, Ed., Calcium Phosphate. Structure, Synthesis, Properties, and Applications, Nova Science Publishers Inc., New York, 2012, ISBN 978-1-62257-299-1

9. N. Groen, M. Guvendiren, H. Rabitz, W.J. Welsh, J. Kohn, and J. de Boer, Stepping into the Omics Era: Opportunities and Challenges for Biomaterials Science, Acta Biomater., 2016, 34, p $133-142$

10. R.A. Surmenev, M.A. Surmeneva, and A.A. Ivanova, Significance of Calcium Phosphate Coatings for the Enhancement of New Bone Osteogenesis-A Review, Acta Biomater., 2014, 10, p 557-570

11. A.H. Choi, B. Ben-Nissan, J.P. Matinlinna, and R.C. Conway, Current Perspectives: Calcium Phosphate Nanocoatings and Nanocomposite Coatings in Dentistry, J. Dent. Res., 2013, 92(10), p 853-859

12. M. Farrokhi-Rad, T. Shahrabi, S. Mahmoodi, and S. Khanmohammadi, Electrophoretic Deposition of Hydroxyapatite-Chitosan-CNTs Nanocomposite Coatings, Ceram. Int., 2017, 43(5), p 4663-4669

13. S.H. Teng, E.J. Lee, C.S. Park, W.Y. Choi, D.S. Shi, and H.E. Kim, Bioactive Nanocomposite Coatings of Collagen/Hydroxyapatite on Titanium Substrates, J. Mater. Sci. Mater. Med., 2008, 19(6), p 2453-2461

14. MedGadget, Worldwide Hip and Knee Orthopedic Surgical Implant Market Shares, Trend, Growth, Strategy and Forecast 2016 to 2022. www.medgadget.com. Accessed 13 March 2018

15. R.B. Heimann and H.D. Lehmann, Bioceramic Coatings for Medical Implants, Wiley-VCH, Weinheim, 2015, ISBN 978-3527-33743-9

16. B. León and J.A. Jansen, Thin Calcium Phosphate Coatings for Medical Implants, Springer, New York, 2009, ISBN 978-0-38777718-4

17. R.B. Heimann, Classic and Advanced Ceramics. From Fundamentals to Applications, Wiley-VCH, Weinheim, 2010, ISBN 978-3-527-32517-7

18. R.B. Heimann, Structure, Properties, and Biomedical Performance of Osteoconductive Bioceramic Coatings, Surf. Coat. Technol., 2013, 233, p 27-38

19. R.B. Heimann, Plasma-Sprayed Hydroxylapatite-Based Coatings: Chemical, Mechanical, Microstructural, and Biomedical Properties, J. Thermal Spray Technol., 2016, 25(5), p 827-850

20. R.B. Heimann, Osseoconductive and Corrosion-Inhibiting Plasma-Sprayed Hydroxylapatite Coatings for Metallic Medical Implants, Metals, 2017, 7(11), p 468-487

21. K. De Groot, R. Geesink, C.P.A.T. Klein, and P. Serekian, Plasma-Sprayed Coatings of Hydroxyapatite, J. Biomed. Mater. Res., 1987, 21, p 1375-1381

22. R. McPherson, N. Gane, and T.J. Bastow, Structural Characterization of Plasma-Sprayed Hydroxylapatite Coatings, $J$. Mater. Sci. Mater. Med., 1995, 6, p 327-334

23. K.A. Gross and C.C. Berndt, Thermal Processing of Hydroxyapatite for Coating Production, J. Biomed. Mater. Res., 1998, 39(4), p 580-587

24. P. Cheang and K.A. Khor, Influence of Powder Characteristics on Plasma-Sprayed Hydroxyapatite Coatings, J. Thermal Spray Technol., 1996, 5(3), p 310-316

25. S.J. Ding, C.P. Ju, and J.H. Lin, Morphology and Immersion Behavior of Plasma-Sprayed Hydroxyapatite/Bioactive Glass Coatings, J. Mater. Sci. Mater. Med., 2000, 11(3), p 183-190

26. R.B. Heimann, Plasma Spray Coating. Principles and Applications, 2nd ed., Wiley-VCH, Weinheim, 2008, ISBN 978-3527-32050-9

27. J.C. Heughebaert and G. Montel, Conversion of Amorphous Tricalcium Phosphate into Apatitic Tricalcium Phosphate, Calcif. Tissue Int., 1982, 34, p S103-S108

28. C. Combes and C. Rey, Amorphous Calcium Phosphates: Synthesis, Properties and Uses in Biomaterials, Acta Biomater., 2010, 6(9), p 3362-3378

29. J. Karthikeyan, C.C. Berndt, J. Tikkanen, J.Y. Wang, A.H. King, and H. Herman, Preparation of Nanophase Materials by Thermal Spray Processing of Liquid Precursors, Nanostruct. Mater., 1997, 9(1-8), p 137-140 
30. K.A. Gross and S. Saber-Samandari, Revealing Mechanical Properties of a Suspension Plasma Sprayed Coating with Nanoindentation, Surf. Coat. Technol., 2009, 203, p 2995-2999

31. R. Jaworski, L. Pawłowski, C. Pierlot, F. Roudet, S. Kozerski, and F. Petit, Recent Developments in Suspension Plasma Sprayed Titanium Oxide and Hydroxyapatite Coatings, $J$. Thermal Spray Technol., 2010, 19(1-2), p 240-247

32. T.J. Callahan and J.B. Gantenberg, Sands BE (1994) Calcium Phosphate (Ca-P) Coating Draft Guidance for Preparation of Food and Drug Administration (FDA) Submissions for Orthopedic and Dental Endosseous Implants, Characterization and Performance of Calcium Phosphate Coatings for Implants, E. Horowitz and J.E. Parr, Ed., ASTM STP 1196, Philadelphia, PA, 1994, p 185-197

33. E. Wintermantel and S.W. Ha, Biokompatible Werkstoffe und Bauweisen. Implantate für Medizin und Umwelt [Biocompatible Materials and Design. Implants for Medicine and Environment], Springer, Berlin, 1996

34. ISO 13779-2, Implants for Surgery-Hydroxyapatite. Part 2: Coatings of Hydroxylapatite (International Organization for Standardization, Geneva, 2008)

35. S. Peroos, Z. Du, and N.H. de Leeuw, A Computer Modelling Study of the Uptake, Structure and Distribution of Carbonate Defects in Hydroxyapatite, Biomaterials, 2006, 27(9), p 2150-2161

36. J.D. Pasteris, C.H. Yoder, and B. Wopenka, Molecular Water in Nominally Anhydrous Carbonated Hydroxylapatite: The Key to a Better Understanding of Bone Mineral, Am. Mineral., 2014, 99, $\mathrm{p}$ 16-27

37. C. Liu, Y. Huang, W. Shen, and J. Cui, Kinetics of Hydroxyapatite Precipitation at $\mathrm{pH} 10$ and 11, Biomaterials, 2001, 22, p 301-306

38. FDA, Guidance for Industry and FDA Staff-Class II Special Controls Guidance Document: Root-form Endosseous Dental Implants and Endosseous Dental Abutments (U.S. Dept. of Health and Human Services, Silver Spring, MD, 2004)

39. FDA, Guidance for Industry and FDA Staff-Non-clinical Information for Femoral Stem Prostheses (U.S. Dept. of Health and Human Services, Silver Spring, MD, 2007)

40. F. Fazan and P.M. Marquis, Dissolution Behavior of PlasmaSprayed Hydroxyapatite Coatings, J. Mater. Sci. Mater. Med., 2000, 11, p 787-792

41. R.B. Heimann, Thermal Spraying of Biomaterials, Surf. Coat. Technol., 2006, 201, p 2012-2019

42. A. Herrera, J. Mateo, J. Gil-Albarova, A. Lobo Escolar, E. Ibarz, S. Gabarre, Y. Más, and L. Gracia, Cementless Hydroxyapatite Coated Hip Prostheses. BioMed. Res. Int., 2015, 2015, Art. ID 386461

43. Y.L. Chen, T. Lin, A. Liu, M.M. Shi, B. Hu, Z.L. Shi, and S.G. Yan, Does Hydroxyapatite Coating Have No Advantage Over Porous Coating in Primary Total Hip Arthroplasty? A MetaAnalysis, J. Orthop. Surg. Res., 2015, 10, p 21

44. W.H. Harris, Traumatic Arthritis of the Hip After Dislocation and Acetabular Fractures: Treatment by Mold Arthroplasty. An End-Result Study Using a New Method of Result Evaluation, $J$. Bone Surg. Am., 1969, 51(4), p 735-755

45. W.M. Capello, J.A. d'Antonio, M.T. Manley, and J.R. Feinberg, Hydroxyapatite in Total Hip Arthroplasty, Clinical Results and Critical Issues, Clin. Orthop. Rel. Res., 1998, 355, p 200-211

46. L. Sun, C.C. Berndt, K.A. Gross, and A. Kucuk, Material Fundamentals and Clinical Performance of Plasma-Sprayed Hydroxyapatite Coatings: A Review, J. Biomed. Mater. Res., 2001, 58, p 570-592

47. J.A. Epinette and M.T. Manley, Ed., Fifteen Years of Clinical Experience with Hydroxyapatite Coatings in Joint Arthroplasty, Springer, Paris, 2004, ISBN 978-2-8178-0851-2
48. A.V. Lombardi, K.R. Berend, and T.H. Mallory, Hydroxyapatite-Coated Titanium Porous Plasma Spray Tapered Stem: Experience at 15 to 18 years, Clin. Orthop. Rel. Res., 2006, 453, p 81-85

49. R. Gandhi, J.R. Davey, and N.N. Mahomed, Hydroxyapatite Coated Femoral Stems in Primary Total Hip Arthroplasty; A Meta-Analysis, J. Arthroplasty, 2009, 24(1), p 38-42

50. A. Herrera, J. Mateo, A. Lobo-Escolar, J.J. Panicello, E. Ibarz, and L. Gracia, Long-Term Outcomes of a New Model of Anatomical Hydroxyapatite-Coated Hip Prostheses, J. Arthroplasty, 2013, 28(7), p 1160-1166

51. H.S. Kim, P.Y. Yun, and Y.K. Kim, Randomized Controlled Clinical Trial of 2 types of Hydroxyapatite-Coated Implants on Moderate Periodontitis Patients, J. Periodontal Implant Sci., 2016, 46(5), p 337-349

52. I. Castellini, L. Andreani, P.D. Parchi, E. Bonicoli, N. Piolanti, F. Risoli, and M. Lisanti, Hydroxyapatite in Total Hip Arthroplasty. Our Experience with a Plasma Spray Porous Titanium Alloy(Hydroxyapatite Double-Coated Cementless Stem, Clin. Cases Miner. Bone Metab., 2016, 13(3), p 221-227

53. T. Albrektsson, Hydroxyapatite-Coated Implants: A Case Against Their Use, J. Oral Maxillofac. Surg., 1998, 56(11), p 1312-1326

54. Y.H. Kim, J.S. Kim, J.H. Joo, and J.W. Park, Is Hydroxyapatite Coating Necessary to Improve Survivorship of Porous-Coated Titanium Femoral Stem? J. Arthroplasty, 2012, 27(4), p 559-563

55. R.B. Heimann, Better Quality Control: Stochastic Approaches to Optimize Properties and Performance of Plasma-Sprayed Coatings, J. Thermal Spray Technol., 2010, 19(4), p 765-778

56. ASTM F1185-03, Standard Specification for Composition of Hydroxyapatite for Surgical Implants, ASTM International, West Conshohocken, PA, 2009, https://doi.org/10.1520/f1185$03 \mathrm{r} 09$

57. ISO 13485, Medical Devices-Quality Management SystemsRequirements for Regulatory Purposes, International Organization for Standardization, Geneva, 2003

58. B.D. Ratner, A.S. Hoffman, F.J. Schoen, and J.E. Lemons, Ed., Biomaterials Science. An Introduction to Materials in Medicine, 3rd ed., Elsevier, Amsterdam, 2013, ISBN 978-0-12-374626-9

59. P. Itiravivong, A. Promasa, T. Laiprasert, T. Techapongworachai, S. Kuptniratsaikul, V. Thanakit, and R.B. Heimann, Comparison of Tissue Reaction and Osteointegration of Metal Implants Between Hydroxyapatite/Ti Alloy Coat: An Animal Experimental Study, J. Med. Assoc. Thailand, 2003, 86(2), p S422-S430

60. S. Mann, Biomineralization. Principles and Concepts in Bioinorganic Materials Chemistry, Oxford University Press, Oxford, 2001, ISBN 978-0-1985-0882-3

61. H.A. Lowenstam and S. Weiner, On Biomineralization, Oxford University Press, New York, 1989, ISBN 978-0-1950-4977-0

62. R.O. Hynes, Integrins: Versatility, Modulation, and Signaling in Cell Adhesion, Cell, 1992, 69(1), p 11-25

63. P. Mandracci, F. Mossano, P. Rivolo, and S. Carossa, Surface Treatments and Functional Coatings for Biocompatibility Improvement and Bacterial Adhesion Reduction in Dental Implantology, Coatings, 2016, 6(1), p 7. https://doi.org/10.3390/ coatings6010007

64. S.I. Stupp and P.V. Braun, Molecular Manipulation of Microstructures: Biomaterials, Ceramics, and Semiconductors, Science, 1997, 277, p 1242-1248

65. H.H. Pan, J.H. Tao, X.R. Xu, and R.K. Tang, Adsorption Processes of Gly and Glu Amino Acids on Hydroxyapatite Surfaces at the Atomic Level, Langmuir, 2007, 23(17), p 8972-8981

66. K. Kandohiro, R. Murata, Y. Yamaguchi, and A. Yoshioka, Protein Adsorption Behavior onto Mn(II)-Doped Calcium 
Hydroxyapatite Particles with Different Morphologies, Colloids Surf. B: Biointerfaces, 2018, 167, p 36-43

67. O. Rahbek, S. Overgaard, M. Lind, K. Bendix, C. Buenger, and K. Søballe, Sealing Effect of Hydroxyapatite Coating on Periimplant Migration of Particles, J. Bone Joint Surg., 2001, 83, p 441-448

68. K. Onuma, A. Oyane, T. Kokubo, G. Treboux, N. Kanzaki, and A. Ito, Precipitation Kinetics of Hydroxyapatite Revealed by the Continuous-Angle Laser Light-Scattering Technique, J. Phys. Chem. B, 2000, 104, p 11950-11956

69. P.F. Schofield, E. Valsami-Jones, I.R. Sneddon, J. Wilson, C.A. Kirk, N.J. Terrill, C.M. Martin, D. Lammie, and T.J. Wess, Nucleation and Growth of Nano-apatite: Applications to Biomineralisation, Geochim. Cosmochim. Acta, 2005, 69(10), p A72-A72 ((Suppl. S.))

70. Q.Q. Hoang, F. Siceri, A.J. Howard, and D.S.C. Yang, Bone Recognition Mechanism of Porcine Osteocalcin from Crystal Structure, Nature, 2003, 425, p 977-980

71. H.C. Anderson, Vesicles Associated with Calcification in the Matrix of Epiphyseal Cartilage, J. Cell Biol., 1969, 41, p 59-72

72. A.L. Boskey and B.L. Dick, The Effect of Phosphatidylserine on In Vivo Hydroxyapatite Growth and Proliferation, Calcif. Tissue Int., 1991, 49(3), p 193-196

73. H. Luo, G. Xiong, C. Zhang, D. Li, Y. Zhu, R. Guo, and Y. Wan, Surface Controlled Calcium Phosphate Formation on Three-Dimensional Bacterial Cellulose-Based Nanofibers, Mater. Sci. Eng. C, 2015, 49, p 526-533

74. K.A. Gross, C.C. Berndt, P. Stephens, and R. Dinnebier, Oxyapatite in Hydroxyapatite Coatings, J. Mater. Sci., 1998, 33, p 3985-3991

75. N. Antolotti, S. Bertini, C. Fanaro, X. Ranz, C. Rey, F. Rusticchelli, and A. Scrivani, Interface characterization of different apatite coatings. In: Thermal Spray. Meeting the Challenges of the 21st Century, C. Coddet (Ed.), Proceedings 15th ITSC, May 25-29, 1998, Nice, France, 1998, p 1121-1126.

76. O. Graßmann and R.B. Heimann, Compositional and Microstructural Changes of Engineered Plasma-Sprayed Hydroxyapatite Coatings on Ti6Al4V Substrates During Incubation in Protein-Free Simulated Body Fluid, J. Biomed. Mater. Res., 2000, 53(6), p 685-693

77. L.Q. Wang, Generalized Fourier Law, Int. J. Heat Mass Transf., 1994, 37(17), p 2627-2634

78. T. Kijima and M. Tsutsumi, Preparation and Thermal Properties of Dense Polycrystalline Oxyhydroxyapatite, J. Am. Ceram. Soc., 1979, 62(9-10), p 455-560

79. P.V. Riboud, Composition et stabilité des phases a structure d'apatite dans le systeme $\mathrm{CaO}-\mathrm{P}_{2} \mathrm{O}_{5}$-oxide de Fer- $\mathrm{H}_{2} \mathrm{O}$ a haute temperature, Ann. Chim., 1973, 8, p 381-390

80. C. Rey, Personal Communication

81. S. Dyshlovenko, B. Pateyron, L. Pawłowski, and D. Murano, Numerical Simulation of Hydroxyapatite Powder Behaviour in Plasma Jet, Surf. Coat. Technol., 2004, 179, p 110-117

82. E.R. Kreidler and F.A. Hummel, Phase Relations in the System SrO- $\mathrm{P}_{2} \mathrm{O}_{5}$ and the Influence of Water Vapor on the Formation of $\mathrm{Sr}_{4} \mathrm{P}_{2} \mathrm{O}_{9}$, Inorg. Chem., 1967, 6(5), p 884-891

83. M.T. Carayon and J.L. Lacout, Study of the Ca/P Atomic Ratio of the Amorphous Phase in Plasma-Sprayed Hydroxyapatite Coatings, J. Solid State Chem., 2003, 172, p 339-350

84. K.A. Gross, C.C. Berndt, and H. Herman, Amorphous Phase Formation in Plasma-Sprayed Hydroxyapatite Coatings, $J$. Biomed. Mater. Res., 1998, 39(3), p 407-414

85. R.B. Heimann and R. Wirth, Formation and Transformation of Amorphous Calcium Phosphates on Titanium Alloy Surfaces During Atmospheric Plasma Spraying and Their Subsequent In Vitro Performance, Biomaterials, 2006, 27, p 823-831
86. J. Götze, H. Hildebrandt, and R.B. Heimann, Charakterisierung des in vitro-Resorptions-verhaltens von plasmagespritzten Hydroxylapatit-Schichten [Characterization of the in vitro resorption behavior of plasma-sprayed hydroxylapatite coatings], BIOmaterialien, 2001, 2(1), p 54-60

87. K.A. Gross and M.R. Phillips, Identification and Mapping of the Amorphous Phase in Plasma-Sprayed Hydroxyapatite Coatings Using Scanning Cathodoluminescence Microscopy, J. Mater. Sci. Mater. Med., 1998, 9(12), p 797-802

88. T.P. Ntsoane, M. Topic, M. Härting, R.B. Heimann, and C. Theron, Spatial and Depth-Resolved Studies of Air PlasmaSprayed Hydroxyapatite Coatings by Means of Diffraction Techniques: Part I, Surf. Coat. Technol., 2016, 294, p 153-163

89. K.A. Gross, V. Gross, and C.C. Berndt, Thermal Analysis of Amorphous Phases in Hydroxyapatite Coatings, J. Am. Ceram. Soc., 1998, 81(1), p 106-112

90. H.V. Tran, Investigation into the Thermal Dehydroxylation and Decomposition of Hydroxyapatite During Atmospheric Plasma Spraying: NMR and Raman Spectroscopic Study of As-Sprayed Coatings and Coatings Incubated in Simulated Body Fluid. Ph.D. Thesis, Department of Mineralogy, Technische Universität Bergakademie Freiberg, Freiberg, Germany, 2004

91. R. Cusco, F. Guitian, S. de Aza, and L. Artus, Differentiation Between Hydroxyapatite and B-Tricalcium Phosphate by Means of $\mu$-Raman Spectroscopy, J. Eur. Ceram. Soc., 1998, 18, p 1301-1305

92. R.B. Heimann, and T.A. Vu, Improvement of Adhesion of Bioceramic Coatings on Jaw and Bone Implants Made from Titanium Alloy. Second Interim Report, SMWK Project No. 7541.82-0390/414, February 15, 1996

93. M. Weinlaender, J. Beumer, III, E.B. Kenney, P.K. Moy, and F. Adar, Raman Microprobe Investigation of the Calcium Phosphate Phase of Three Commercially Available Plasma-FlameSprayed Hydroxyapatite Coated Dental Implants, J. Mater. Sci. Mater. Med., 1992, 3, p 397-401

94. I. Demnati, D. Grossin, C. Combes, and C. Rey, Plasma-Sprayed Apatite Coatings: Review of Physical-Chemical Aspects and Their Biological Consequences, J. Med. Biol. Eng., 2014, 34, p 1-7

95. I. Demnati, D. Grossin, O. Marsan et al., Comparison of Physical-Chemical and Mechanical Properties of Chlorapatite and Hydroxyapatite Plasma Sprayed Coatings, Open Biomed. Eng. J., 2015, 9, p 42-55

96. U. Posset, E. Löcklin, R. Thull, and W. Kiefer, Vibrational Spectroscopic Study of Tetracalcium Phosphate in Pure Polycrystalline Form and as a Constituent of a Self-Setting Bone Cement, J. Biomed. Mater. Res., 1998, 40, p 640-645

97. R.B. Heimann, Novel Approaches Towards Design and Biofunctionality of Plasma-Sprayed Osteoconductive Calcium Phosphate Coatings for Biomedical Implants: The Concept of Bond Coats, Trends in Biomaterials Research, P.J. Pannone, Ed., Nova Science Publishers Inc., New York, 2007, p 1-80

98. H.M. Kim, T. Miyazaki, T. Kokubo, and T. Nakamura, Revised Simulated Body Fluid, Bioceramics, 2001, 13, p 47-50

99. R.B. Heimann, H.V. Tran, and P. Hartmann, Laser-Raman and Nuclear Magnetic Resonance (NMR) Studies on PlasmaSprayed Hydroxyapatite Coatings: Influence of Bioinert Bond Coats on Phase Composition and Resorption Kinetics in Simulated Body Fluid, Mater.-wiss. Werkstofftechn., 2003, 34(12), p 1163-1169

100. P. Hartmann, C. Jäger, S. Barth, J. Vogel, and K. Meyer, Solid State NMR, X-Ray diffraction, and Infrared Characterization of Local Structure in Heat-Treated Oxyhydroxyapatite Microcrystals: An Analogy of the Thermal Deposition of Hydroxyapatite During Plasma-Spray Procedure, J. Solid State Chem., 2001, 160, p 460-468 
101. C. Jäger, T. Welzel, W. Meyer-Zaika, and M. Epple, A SolidState NMR Investigation of the Structure of Nanocrystalline Hydroxyapatite, Magn. Reson. Chem., 2006, 44, p 573-580

102. C. Jäger, S. Maltsev, and A. Karrasch, Progress of Structural Investigation of Amorphous Calcium Phosphate (ACP) and Hydroxyapatite (HAp): Disorder and Surfaces as seen by Solid State NMR, Key Eng. Mater., 2006, 309-311, p 69-72

103. D. McConnell and M.H. Hey, The Oxyapatite (Voelckerite) Problem, Min. Mag., 1969, 37(86), p 301-303

104. J.A. Voelcker, Die chemische Zusammensetzung des Apatits nach eigenen vollständigen Analysen [Chemical composition of apatite according to complete analyses sui generis], Ber. Deutsch. Chem. Ges., 1883, 16, p 2460-2464

105. A.F. Rogers, A New Locality for Voelckerite and the Validity of Voelckerite as a Mineral Species, Min. Mag., 1914, 17, p 155162

106. F. Korber and G. Trömel, Untersuchungen über Kalk-Phosphorsäure- und Kalk-Phosphorsäure-Kieselsäure-Verbindungen [Investigation on Lime-Phosphoric Acid and Lime-Phosphoric Acid-Silicic Acid Compounds], Z. Elektrochemie, 1932, 38, p 578-582

107. M.A. Bredig, H.H. Franck, and H. Füldner, Beiträge zur Kenntnis der Kalk-Phosphorsäure-Verbindungen II, [Contributions to the Knowledge of Lime-Phosphoric Acid Compounds II], Z. Elektrochemie, 1933, 39, p 959-969

108. N. De Leeuw, J.R. Bowe, and J.A.L. Rabone, A computational Investigation of Stoichiometric and Calcium-Deficient Oxy- and Hydroxyapatite, Faraday Discuss., 2007, 134, p 195-214

109. P. Alberius Henning, A. Landa-Canovas, A.K. Larsson, and S. Lidin, The Structure of Oxyapatite Solved by HREM, Acta Cryst. B, 1999, 55, p 170-176

110. L. Calderin, M.J. Stott, and A. Rubio, Electronic and Crystallographic Structure of Apatite, Phys. Rev. B, 2003, 67, p 134106-134112

111. C.J. Liao, F.H. Lin, K.S. Chen, and J.S. Sun, Thermal Decomposition and Reconstruction of Hydroxyapatite in Air Atmosphere, Biomaterials, 1999, 20, p 1807-1813

112. J.C. Trombe and G. Montel, Sur la préparation del'oxyapatite phospho-calcique, C. R. Acad. Sci. Paris, 1971, 273, p 462-465

113. J.C. Trombe, Contribution á l'étude de la decomposition et de la réactivité de certaines apatites hydroxylées et carbonates, Ann. Chim. (Paris), 14th Ser., 1973, 8, p 335-347

114. R.B. Heimann, Characterisation of As-Sprayed and Incubated Hydroxyapatite Coatings with High Resolution Techniques, Mater.-wiss. Werkstofftechn., 2009, 40(1-2), p 21-30

115. G. Montel, G. Bonel, J.C. Trombe, J.C. Heughebaert, and C. Rey, Progress dans le domaine de la chimie des composes phosphores solides a structure d'apatite, Pure Appl. Chem., 1980, 52(4), p 973-987

116. I. Demnati, M. Parco, D. Grossin, I. Fagoaga, C. Drouet, G. Barykin, C. Combes, I. Braceras, S. Gonsalves, and C. Rey,
Hydroxyapatite Coating on Titanium by a Low Energy Plasma Spraying Mini-Gun, Surf. Coat. Technol., 2012, 206, p 23462353

117. R.B. Heimann, Tracking the Thermal Decomposition of PlasmaSprayed Hydroxylapatite, Am. Mineral., 2015, 100(11-12), p 2419-2425

118. P. Ducheyne, S. Radin, and L. King, The Effect of Calcium Phosphate Ceramic Composition and Structure on In Vitro Behavior. I. Dissolution, J. Biomed. Mater. Res., 1993, 27, p 534

119. R.Z. LeGeros, Calcium Phosphates in Oral Biology and Medicine, Monographs in Oral Science Karger, Basel, 1991

120. R.G. Courtney-Harris, M.V. Kayser, and S. Downes, Comparison of the Early Production of Extracellular Matrix on Dense Hydroxyapatite and Hydroxyapatite-Coated Titanium in Cell and Organ Culture, Biomaterials, 1994, 16(6), p 489-495

121. R.Z. LeGeros, I. Orly, M. Gregoire, and G. Daculsi, Substrate Surface Dissolution and Interfacial Biological Mineralization, The Bone-Biomaterials Interface, J.E. Davies, Ed., University of Toronto Press, Toronto, 1991, p 76-88

122. L. Chou, B. Marek, and W.R. Wagner, Effect of Hydroxyapatite Coating Crystallinity on Biosolubility, Cell Attachment Efficiency and Proliferation In Vitro, Biomaterials, 1999, 19, p $977-$ 985

123. R.B. Heimann, Design of Novel Plasma-Sprayed Hydroxyapatite-Bond Coat Bioceramic Systems, J. Thermal Spray Technol., 1999, 8(4), p 597-604

124. B.S. Ng, I. Annergren, A.M. Soutar, K.A. Khor, and A.E. Jarfors, Characterisation of a Duplex $\mathrm{TiO}_{2} / \mathrm{CaP}$ Coating on Ti6Al4V for Hard Tissue Replacement, Biomaterials, 2005, 26(10), p 1087-1095

125. M.S. Tung and D. Skrtic, Interfacial Properties of Hydroxyapatite, Fluoroapatite and Octacalcium Phosphate, Octacalcium Phosphate. Monographs in Oral Science, Vol 8, L.C. Chow and E.D. Eanes, Ed., Karger, Basel, 2001, p 112-129

126. P. Hartman and W. Perdok, On the Relation Between Structure and Morphology of Crystals, Acta Cryst., 1955, 8, p 49-52

127. R.A. Terpstra, P. Bennema, P. Hartman, C.F. Woensdregt, W.G. Perdok, and M.L. Senechal, F Faces of Apatite and Its Morphology: Theory and Observation, J. Crystal Growth, 1986, 78, p 468-478

128. J. Weng, Y. Cao, J. Chen, and X. Zhang, Significance of Water Promoting Amorphous to Crystalline Conversion of Apatite in Plasma Sprayed Coatings, J. Mater. Sci. Lett., 1995, 14, p 211213

129. T. Albrektsson, B. Chrcanovic, M. Jacobsson, and A. Wennerberg, Osseointegration of Implants-A Biological and Clinical Overview, JSM Dent. Surg., 2017, 2(3), p 1022

130. Z. Othman, B.C. Pastor, S. van Rijt, and P. Habibovic, Understanding Interaction Between Biomaterials and Biological Systems Using Proteomics, Biomaterials, 2018, 167, p 191-204 